\title{
CONTRASTES ENTRE A METRÓPOLE E O INTERIOR FLUMINENSE A PARTIR DA DINÂMICA POPULACIONAL
}

\author{
CONSIDERATIONS ON RIO DE JANEIRO STATE'S \\ POPULATION DYNAMICS: CONTRASTS BETWEEN \\ METROPOLIS AND HINTERLAND
}

\author{
Dr. Miguel Angelo Ribeiro (Instituto de Geografia - UERJ) \\ mamikisi@gmail.com \\ Dra Maria Monica Vieira Caetano O' Neill (Coordenação de Geografia - IBGE) \\ monica.oneill@skydome.com.br
}

"Na virada do século, quase metadade da humanidade viverá em cidades; o mundo do século XXI será predominantemente urbano" (O GLOBO, 2012).

\section{Resumo}

O artigo em tela procura, a partir dos resultados do Censo Demográfico - 2010 (IBGE), segundo alguns dados demográficos selecionados, tais como: população residente total, taxa média geométrica de crescimento, população urbana e rural e população da sede municipal, analisar e compreender a dinâmica populacional fluminense. Para tanto, as questões norteadoras da pesquisa são: (i) Como se apresenta distribuída a população em território fluminense?; (ii) Que comparações podem ser estabelecidas entre os dados censitários atuais, com os resultados do Censo Demográfico - 2000?; (iii) Que fatores explicam estes resultados estatísticos?

Traços marcantes de desequilíbrios são visíveis ao retratar a dinâmica populacional em território fluminense. Verificam-se expressivos descompassos entre a metrópole do Rio de Janeiro e sua hinterlândia, entre o núcleo e a periferia metropolitanos e entre o urbano e o rural tendo como resultado um quadro de concentração populacional. Este processo resulta de taxas de crescimento anual diferenciadas em alguns municípios e que ao longo dos anos privilegiaram o núcleo metropolitano e sua periferia, reforçado pela localização maciça da população estadual em áreas urbanas (cidades e vilas), segundo critério oficial adotado pelo IBGE. 
Palavras-chave: dinâmica populacional, população urbana e rural, distribuição populacional, metrópole e interior fluminense.

\begin{abstract}
This paper seeks to analyze and understand the dynamics of Rio de Janeiro state's population. It does so based on IBGE's 2010 Census results, especially demographic data such as total resident population, geometric average rate of growth, urban and rural population, and population living in the city of Rio de Janeiro. Its starting point is the following questions: How is the population distributed within Rio de Janeiro state's territory? Which comparisons could be made between current Census results and those ones from 2000 Census? Which factors could explain such statistical results? Some relevant traces of instability are visible when it comes to show Rio de Janeiro state's population dynamics. One verifies expressive divergences between the metropolis of Rio de Janeiro and its hinterland, between metropolitan nucleus and periphery, and between urban areas and rural ones, which result in concentration of population. This process stems from differentiated rates of annual growth in some municipalities that privilege the metropolitan nucleus and its periphery throughout the years. According to official criterion adopted by IBGE, this process is reinforced by the massive presence of population in urban areas (towns and cities).
\end{abstract}

Keywords: population dynamics, rural and urban population, population distribution, Rio de Janeiro metropolis and hinterland.

\title{
Introdução
}

A cidade do Rio de Janeiro e sua periferia destacam-se no cenário nacional pelo porte populacional, era a primeira em tamanho e, atualmente, assumiu a segunda posição no país. Em 1900 a população do município do Rio de Janeiro era três vezes maior que a de São Paulo, esta relação diminuiu ao longo das décadas e em 1960 o Rio de Janeiro foi superado por São Paulo. Nas décadas de 1980, 1991 e 2000, o Rio de Janeiro apresentou um quadro de estagnação econômica e demográfica que manteve o município com população pouco acima de cinco milhões, enquanto São Paulo já alcançava o dobro deste valor em 2000 e 2010.

Geo UERJ - Ano 14, no. 23, v. 1, $1^{\circ}$ semestre de 2012 p. 262-301

ISSN: 1415-7543 E-ISSN: 1981-9021

http://www.e-publicacoes.uerj.br/index.php/geouerj 
Desde a fusão dos estados da Guanabara e do antigo estado do Rio de Janeiro, ocorrida em 1975, verifica-se em escala estadual outro processo que é o de concentração e hegemonia populacional na capital fluminense - a cidade do Rio de Janeiro, e nos limites metropolitanos diante do interior ${ }^{1}$. Apesar desta distribuição populacional diferenciada, nestes mais de 35 anos de fusão, o interior apresenta crescimento relativo expressivo, frente ao núcleo e a periferia metropolitanos, onde alguns municípios apresentam totais populacionais com destaque no contexto estadual, a exemplo de municípios localizados nas regiões das Baixadas Litorâneas: Araruama, Cabo Frio, Rio das Ostras; na Costa Verde: Angra dos Reis, Mangaratiba e no Médio Paraíba: Resende (mapa 1) nos quais o dinamismo economico se evidencia mais recentemente. Contudo, quando comparados com alguns municípios localizados no espaço metropolitano, os quantitativos são menores em termos absolutos.

Mapa 1: Regiões de Governo Fluminenses

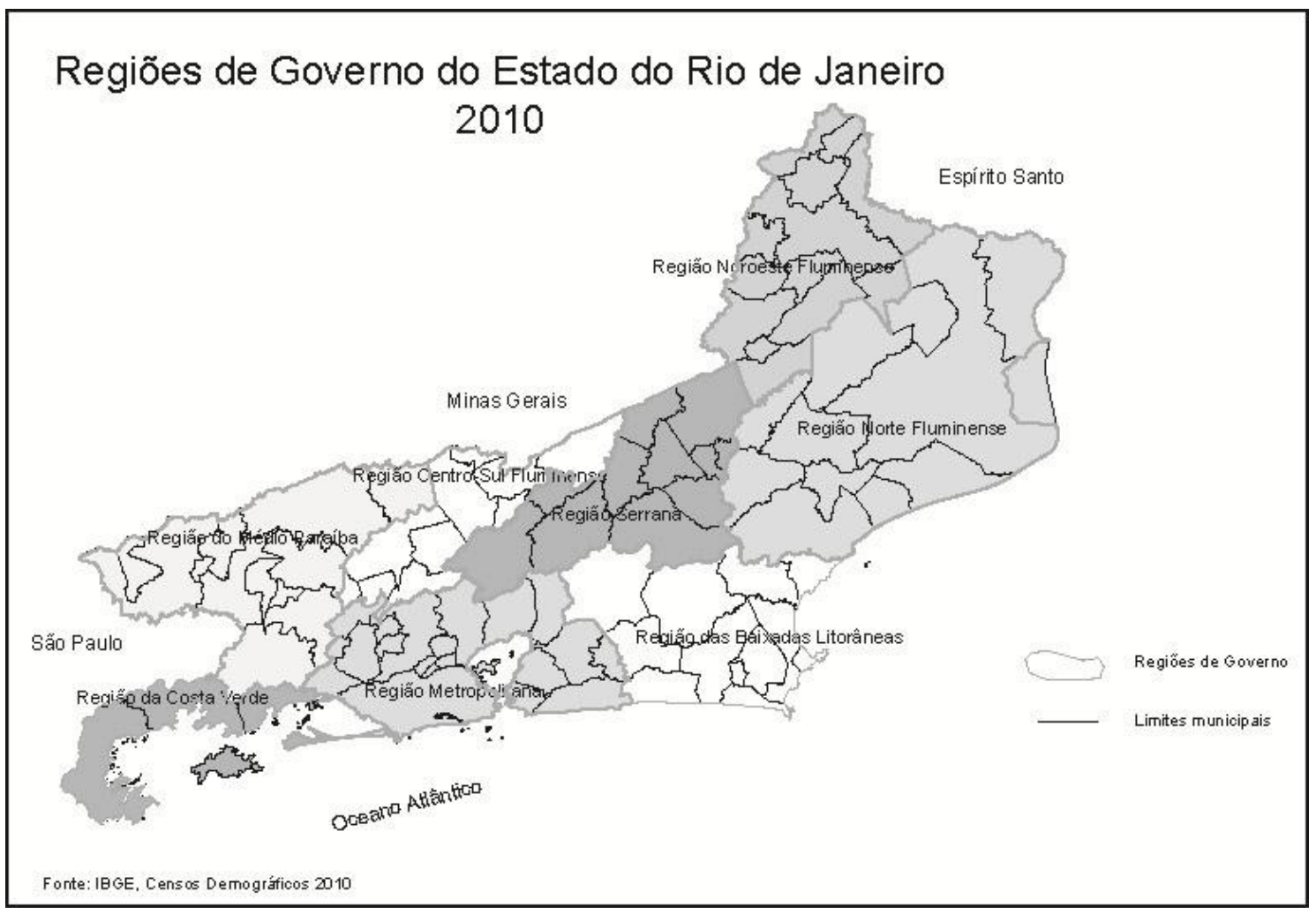

Geo UERJ - Ano 14, no. 23, v. 1, $1^{\circ}$ semestre de 2012 p. 262-301 ISSN: 1415-7543 E-ISSN: 1981-9021 http://www.e-publicacoes.uerj.br/index.php/geouerj 
Outro fato a ser destacado quanto ao Estado do Rio de Janeiro, são os resultados mais recentes do Censo de 2010 que apontam mudanças na sua demografia, o Estado deixa de ser uma área de baixa evasão, absorvedor de população, e torna-se uma área de rotatividade migratória com um saldo migratório negativo (OLIVEIRA, ERVATTI e O’NEILL, 2011).

Percebemos nesta primeira década do século 21, nesta unidade federada, que a questão demográfica apresenta singularidades nos contextos nacional e estadual.

Posto isto, o artigo em tela procura, a partir dos resultados do Censo Demográfico - 2010 (IBGE), segundo alguns dados demográficos selecionados, tais como: população residente total, taxa média geométrica de crescimento, população urbana e rural e população da sede municipal, analisar e compreender a dinâmica populacional fluminense. Para tanto, as questões norteadoras da pesquisa são: (i) Como se apresenta distribuída a população em território fluminense?; (ii) Que comparações podem ser estabelecidas entre os dados censitários atuais, com os resultados do Censo Demográfico - 2000?; (iii) Que fatores explicam estes resultados estatísticos?

Os traços marcantes destes desequilíbrios são visíveis ao retratar a dinâmica populacional em território fluminense. Verificam-se expressivos descompassos entre a metrópole do Rio de Janeiro e sua hinterlândia, entre o núcleo e a periferia metropolitanos e entre o urbano e o rural tendo como resultado um quadro de concentração populacional. Este processo resulta de taxas de crescimento anual ${ }^{2}$ diferenciadas em alguns municípios e que ao longo dos anos privilegiaram o núcleo metropolitano e sua periferia, reforçado pela localização maciça da população estadual em áreas urbanas (cidades e vilas), segundo critério oficial adotado pelo IBGE $^{3}$.

Para dar conta do objetivo e dos questionamentos formulados, o artigo apresenta-se estruturado em três partes. A primeira trata em analisar a distribuição espacial da população fluminense; a segunda procura discutir as taxas geométricas anuais, sua dinâmica e distribuição, seus padrões e fatores que influenciaram nestes resultados. Por fim, discute-se a repartição da população urbana e rural, conforme a localização do domicílio, além da elaboração de uma tipologia que diminua as 
distorções verificadas com a delimitação de urbano e rural, no qual é adotado o critério político-administrativo.

\section{A Concentração Metropolitana da População Fluminense}

O estado do Rio de Janeiro é dominado pelo peso da concentração metropolitana, ou seja, é na região metropolitana, instituída por lei federal em 1969, e atualmente constituída por dezenove municípios ${ }^{4}$ que está concentrada grande parte da população estadual, fato que se consolidou antes mesmo da fusão (RIBEIRO, 2002).

Segundo os resultados do Censo Demográfico 2010 (IBGE) aproximadamente 11.838.752 indivíduos residem nos limites metropolitanos, correspondendo a $74,1 \%$ da população estadual, na qual acusou 15.974.617 habitantes, conforme indicado na tabela 1.

Tabela 1 - Estado do Rio de Janeiro: Dados Demográficos Selecionados - 2000/2010

\begin{tabular}{|c|c|c|c|c|c|c|}
\hline \multirow{2}{*}{$\begin{array}{c}\text { Estado, Região } \\
\text { Metropolitana e }\end{array}$} & \multicolumn{2}{|c|}{$\begin{array}{c}\text { População Residente } \\
\text { Interior }\end{array}$} & \multirow{2}{*}{$\begin{array}{c}\text { Crescimento } \\
\text { Absoluto }\end{array}$} & \multicolumn{2}{|c|}{$\begin{array}{c}\text { Participação } \\
\text { Relativa }\end{array}$} & \multicolumn{2}{c|}{$\begin{array}{c}\text { Taxa Média } \\
\text { Geométrica de } \\
\text { Crescimento Anual } \\
\text { (\%) a.a.) 2000/2010 }\end{array}$} \\
\cline { 6 - 7 } & $\mathbf{2 0 0 0}$ & $\mathbf{2 0 1 0}$ & $\mathbf{2 0 0 0 / 2 0 1 0}$ & $\mathbf{2 0 0 0}$ & $\mathbf{2 0 1 0}$ & 1,05 \\
\hline ESTADO & 14.393 .282 & 15.974 .617 & 1.581 .335 & 100,0 & 100,0 & 0,86 \\
\hline Região Metropolitana & 10.869 .255 & 11.838 .752 & 969.497 & 75,5 & 74,1 & 0,77 \\
\hline Núcleo & 5.857 .904 & 6.323 .037 & 465.133 & 40,6 & 39,5 & 0,96 \\
\hline Periferia & 5.011 .351 & 5.515 .715 & 504.364 & 34,8 & 34,5 & 1,61 \\
\hline Interior & 3.524 .927 & 4.135 .867 & 610.940 & 24,4 & 25,8 & \\
\hline
\end{tabular}

Fonte: IBGE - Censo Demográfico 2000 e 2010

Do total dos mais de 11 milhões de habitantes, residentes na Região Metropolitana, 6.323.037 vivem no núcleo metropolitano, ou seja, no município do Rio de Janeiro, concentrando 39,5\% da população estadual; enquanto 5.515.715, 
correspondendo a 34,5\% residem na periferia metropolitana, e $4.135 .867(25,8 \%)$ habitam o restante do estado, correspondendo a 73 municípios do interior.

Se compararmos estes totais com aqueles registrados no Censo 2000, observamos que apenas o conjunto dos municípios localizados no interior apresentou crescimento relativo significativo, pois registraram 24,4\% e 25,8\% nos Censos de 2000 e de 2010 , respectivamente.

Tais resultados apontam que há uma tendência de diminuição relativa das populações residentes nos limites metropolitanos, principalmente no núcleo em relação a periferia e, destes em relação ao interior, fato verificado a partir dos anos 1990 no contexto brasileiro e que pode ser exemplificado para esta unidade federada.

Dos 26 municípios mais populosos do Estado e que acusaram população residente superior a cem mil habitantes em 2010, quatorze estão localizados nos limites metropolitanos e doze no interior, conforme indicado na tabela 2.

Tabela 2 - Estado do Rio de Janeiro: Municípios mais Populosos - 2010 - 2000 - 1991

\begin{tabular}{|c|c|c|c|c|c|c|}
\hline Municípios & $\mathbf{2 0 1 0}$ & Posição & $\mathbf{2 0 0 0}$ & Posição & $\mathbf{1 9 9 1}$ & Posição \\
\hline Rio de Janeiro & 6.323 .037 & 1 & 5.857 .904 & 1 & 5.480 .768 & 1 \\
\hline São Gonçalo & 999.901 & 2 & 891.119 & 2 & 779.832 & 3 \\
\hline Duque de Caxias & 855.046 & 3 & 775.456 & 3 & 667.821 & 4 \\
\hline Nova Iguaçu & 795.212 & 4 & 753.327 & 4 & 1.297 .704 & 2 \\
\hline Niterói & 487.327 & 5 & 459.451 & 5 & 436.155 & 5 \\
\hline Belford Roxo* & 469.261 & 6 & 434.474 & 7 & - & - \\
\hline Campos dos Goytacazes & 463.545 & 7 & 406.989 & 8 & 389.109 & 7 \\
\hline São João de Meriti & 459.356 & 8 & 449.476 & 6 & 425.772 & 6 \\
\hline Petrópolis & 296.044 & 9 & 286.537 & 9 & 255.468 & 8 \\
\hline Volta Redonda & 257.996 & 10 & 242.063 & 10 & 220.305 & 9 \\
\hline Magé & 228.150 & 11 & 205.830 & 11 & 191.734 & 10 \\
\hline Itaboraí & 218.090 & 12 & 187.479 & 12 & 162.742 & 13 \\
\hline Macaé & 206.748 & 13 & 132.461 & 18 & 100.895 & 17 \\
\hline Cabo Frio & 186.222 & 14 & 126.828 & 19 & 84.915 & 20 \\
\hline Nova Friburgo & 182.016 & 15 & 173.418 & 13 & 167.081 & 12 \\
\hline Barra Mansa & 177.861 & 16 & 170.753 & 14 & 172.216 & 11 \\
\hline Mesquita* & 168.403 & 17 & 167.272 & 15 & - & - \\
\hline Teresópolis & 163.805 & 18 & 138.081 & 17 & 120.709 & 15 \\
\hline
\end{tabular}

Geo UERJ - Ano 14, nº. 23, v. 1, $1^{\circ}$ semestre de 2012 p. 262-301

ISSN: 1415-7543 E-ISSN: 1981-9021

http://www.e-publicacoes.uerj.br/index.php/geouerj 


\begin{tabular}{|c|c|c|c|c|c|c|}
\hline Nilópolis & 157.483 & 19 & 153.712 & 16 & 158.092 & 14 \\
\hline Angra dos Reis & 148.294 & 20 & 119.247 & 21 & 85.571 & 19 \\
\hline Queimados* & 137.938 & 21 & 121.993 & 20 & - & - \\
\hline Maricá & 127.519 & 22 & 76.737 & 28 & 46.545 & 28 \\
\hline Resende & 119.801 & 23 & 104.549 & 22 & 91.757 & 18 \\
\hline Araruama & 112.028 & 24 & 82.803 & 26 & 59.024 & 26 \\
\hline Itaguá & 109.163 & 25 & 82.003 & 27 & 113.057 & 16 \\
\hline Rio das Ostras* & 105.757 & 26 & 36.419 & 42 & - & - \\
\hline Total & 13.956 .003 & - & 12.636 .381 & - & 11.507 .272 & - \\
\hline
\end{tabular}

* Em 1991 eram considerados distritos

Fonte: IBGE - Censo Demográfico 2010, 2000 e 1991

Este conjunto de 26 municípios agrega 13.956.003 de residentes, representando $87,3 \%$ da população estadual, estando 11.535.886 habitantes localizados na Região Metropolitana, correspondendo a 72,2\% e 2.257 .950 no interior fluminense, ou seja, $14,1 \%$ da população total estadual. Tais valores reforçam o padrão concentrador verificado pois ocorrem em apenas 28,3\% dos 92 municípios do estado, sendo esta concentração mais evidente na metrópole.

Como pode ser observado na tabela 2 , houve uma variação na posição dos municípios quando se comparam os dois anos censitários, mas as cinco primeiras posições foram mantidas com municípios integrantes da metrópole, sendo que o Rio de Janeiro destaca-se dos demais no tocante à concentração populacional. A partir da sexta posição há uma variação da posição ocupada pelos demais municípios. O município mais expressivo neste conjunto é Rio das Ostras que apresentou total populacional bastante significativo na última década, passando da $42^{\mathrm{a}}$ para a $26^{\mathrm{a}}$ posição, resultado que será comentado posteriormente.

Cumpre fazer referência que os doze municípios considerados fora dos limites metropolitanos são aqueles mais dinâmicos do interior fluminense, e que vêm passando por profundas transformações econômicas, alicerçadas na exploração petrolífera na plataforma continental e recebendo os aludidos royalties e participações especiais; na atividade turística e de lazer, nas recentes atividades industriais, além da implementação de novas atividades agropecuárias, como apontou Marafon e Ribeiro (2010). 
O perfil metropolitano de concentração populacional afirmou-se desde passado remoto, principalmente em seu núcleo, o município do Rio de Janeiro, como apontou Davidovich (2000). Tal situação acentua-se para a cidade do Rio de Janeiro, quando passa a exercer a função de capital do país, além de deter outras funções, como a portuária e a comercial, provocando significativa atração populacional. Esta concentração eclode com o papel de núcleo metropolitano a partir dos anos de 1940, quando do início da formação da Área Metropolitana, atraindo levas de migrantes proveninentes principalmente, do Nordeste; culmina nos anos de 1960, e ratifica este papel em anos posteriores, assumindo tal hegemonia (RIBEIRO, 2002).

No processo de formação da Área Metropolitana do Rio de Janeiro, a malha construída do núcleo espraiou-se em direção à periferia - Baixada fluminense, além de ocupar o lado oriental da Baía de Guanabara, notadamente os municípios de Niterói, São Gonçalo e Itaboraí. Por outro lado, o tecido urbano sofreu um processo de esgarçamento, fato evidenciado, em grande parte das metrópoles brasileiras, principalmente em suas periferias carentes de infra-estrutura.

Posto isto, os valores expressos nas tabelas anteriores para o estado, a região metropolitana, o interior e para os municípios são resultantes das taxas de crescimento anual entre 2000 e 2010, e que serão analisadas na próxima seção.

\section{As Taxas Geométricas de Crescimento Fluminense}

A taxa de crescimento da população incorpora dois componentes: o crescimento vegetativo, que conforme o local denota uma tendência que pode ser resultado de $n$ fatores, dentre eles a fecundidade, e o componente migratório, que aponta o maior ou menor dinamismo das localidades (OLIVEIRA, ERVATTI E O’NEILL, 2011). No caso brasileiro, se o país cresceu a uma taxa de 1,17\%, abaixo das décadas anteriores, significa não só uma diminuição do ritmo, mas também que se pode deduzir que qualquer localidade no Brasil com um crescimento acima de 1,50\%, valor estipulado pelos pesquisadores, tem como principal responsável os deslocamentos de população (migração). Sendo assim, podemos definir quais localidades são mais dinâmicas e 
porque estão atraindo pessoas. No caso brasileiro destacam-se as fronteiras agrícolas e de resursos, exemplificadas por porções da Amazônia; de modo geral, o litoral com atividades turísticas, ligadas ao petróleo e gás, e aqui, alguns municípios fluminenses estão inseridos, além de municípios que se destacam por dinâmicas específicas.

$\mathrm{Na}$ escala nacional, a tendência verificada é que o ritmo de crescimento anual diminuiu em algumas aglomerações, mas o segundo escalão de metrópoles e grandes cidades com mais de cem mil habitantes continuam crescendo. Como apontou Baeninger (s/d, p. 273/4),

o ritmo de crescimento da população brasileira em seu conjunto vem perdendo intensidade a partir dos anos 60, em função da acentuada queda da fecundidade (de cerca de 6 filhos por mulher em 1960 passou-se a 2,35 em 2000). Assim, de uma taxa de crescimento correspondente a 3,05\% a.a. no período 1950-1960, baixou-se para 2,48\% a.a. nos anos 1970 , passando a 1,93 a.a. no período 1980-1991. No período 1991-2000, a taxa de crescimento da população brasileira chegou a $1,06 \%$ a.a.

No tocante ao estado do Rio de Janeiro o que foi constatado com os resultados do Censo Demográfico 2010, em relação ao Censo 2000 é que esta unidade federada registrou uma taxa de crescimento de 1,05\% a.a., inferior a registrada no período 19912000 de 1,75\% a.a. A Região Metropolitana apenas acusou crescimento de 0,86\% a.a., enquanto o núcleo registrou $0,77 \%$ a.a. e a periferia $0,96 \%$ a.a. Os valores alcançados na escala metropolitana indicam que a população não está sendo reposta, e que a continuar este ritmo as perdas irão se tornar maiores no futuro. $\mathrm{O}$ interior, por sua vez, possui dinâmica própria, pois apresentou uma taxa de crescimento maior, superior ao Estado e a região metropolitana, da ordem de 1,61\% a.a., podendo-se aferir que este resultado é proveniente de migração, já que as taxas de natalidade caíram no estado (OLIVEIRA, ERVATTI e O'NEILL, 2011).

Quanto aos municípios fluminenses podemos destacar 45 que registraram totais superiores a média estadual, ou seja, de $1,06 \%$ a.a. até $11,25 \%$ a.a. conforme indicado na tabela 3 . 
Tabela 3 - Estado do Rio de Janeiro: Taxas Geométricas de Crescimento 2000 2010

\begin{tabular}{|c|c|c|c|c|}
\hline & Municipio & $\begin{array}{c}\text { População Total } \\
2000\end{array}$ & $\begin{array}{c}\text { População Total } \\
2010\end{array}$ & $\begin{array}{c}\text { Tx Cresc } 2000-2010 \\
(\% \text { a.a. })\end{array}$ \\
\hline 1 & Rio das Ostras & 36419 & 105757 & 11,25 \\
\hline 2 & Maricá & 76737 & 127519 & 5,21 \\
\hline 3 & Casimiro de Abreu & 22152 & 35373 & 4,79 \\
\hline 4 & Macaé & 132461 & 206748 & 4,55 \\
\hline 5 & Carapebus & 8666 & 13348 & 4,41 \\
\hline 6 & Iguaba Grande & 15089 & 22858 & 4,24 \\
\hline 7 & Armação dos Búzios & 18204 & 27538 & 4,23 \\
\hline 8 & Quissamã & 13674 & 20244 & 4,00 \\
\hline 9 & Cabo Frio & 126828 & 186222 & 3,92 \\
\hline 10 & Mangaratiba & 24901 & 36311 & 3,84 \\
\hline 11 & Angra dos Reis & 119247 & 148294 & 3,57 \\
\hline 12 & Saquarema & 52461 & 74221 & 3,53 \\
\hline 13 & São Pedro da Aldeia & 63227 & 88013 & 3,36 \\
\hline 14 & Porto Real & 12095 & 16574 & 3,20 \\
\hline 15 & Guapimirim & 37952 & 51487 & 3,10 \\
\hline 16 & Araruama & 82803 & 112028 & 3,07 \\
\hline 17 & Itaguaí & 82003 & 109163 & 2,90 \\
\hline 18 & Aperibé & 8018 & 10215 & 2,45 \\
\hline 19 & Parati & 29544 & 37575 & 2,43 \\
\hline 20 & VarreSai & 7854 & 9503 & 1,92 \\
\hline 21 & Seropédica & 65260 & 78183 & 1,82 \\
\hline 22 & Quatis & 10730 & 12831 & 1,80 \\
\hline 23 & Piraí & 22118 & 26309 & 1,75 \\
\hline 24 & Teresópolis & 138081 & 163805 & 1,72 \\
\hline 25 & São João da Barra & 27682 & 32767 & 1,70 \\
\hline 26 & Tanguá & 26057 & 30731 & 1,66 \\
\hline 27 & Pinheiral & 19481 & 22724 & 1,55 \\
\hline 28 & Itatiaia & 24739 & 28852 & 1,55 \\
\hline 29 & Itaboraí & 187479 & 218090 & 1,52 \\
\hline 30 & Arraial do Cabo & 23877 & 27770 & 1,52 \\
\hline 31 & Paracambi & 40475 & 47074 & 1,52 \\
\hline 32 & Areal & 9899 & 11421 & 1,44 \\
\hline
\end{tabular}

Geo UERJ - Ano 14, no. 23, v. 1, $1^{\circ}$ semestre de 2012 p. 262-301

ISSN: 1415-7543 E-ISSN: 1981-9021

http://www.e-publicacoes.uerj.br/index.php/geouerj 


\begin{tabular}{|c|c|c|c|c|}
\hline 33 & Resende & 104549 & 119801 & 1,37 \\
\hline 34 & Japeri & 83278 & 95391 & 1,37 \\
\hline 35 & Carmo & 15289 & 17439 & 1,32 \\
\hline 36 & Campos dos Goytacazes & 406989 & 463545 & 1,31 \\
\hline 37 & Queimados & 121993 & 137938 & 1,24 \\
\hline 38 & Conceição de Macabu & 18782 & 21200 & 1,22 \\
\hline 39 & São Gonçalo & 891119 & 999901 & 1,16 \\
\hline 40 & Bom Jardim & 22651 & 25398 & 1,15 \\
\hline 41 & Rio das Flores & 7625 & 8545 & 1,15 \\
\hline 42 & Cachoeiras de Macacu & 48543 & 54370 & 1,14 \\
\hline 43 & Rio Bonito & 49691 & 55586 & 1,13 \\
\hline 44 & Porciúncula & 15952 & 17771 & 1,09 \\
\hline 45 & Italva & 12621 & 14027 & 1,06 \\
\hline 46 & Magé & 205830 & 228150 & 1,03 \\
\hline 47 & Itaperuna & 86720 & 95876 & 1,01 \\
\hline 48 & Duque de Caxias & 775456 & 855046 & 0,98 \\
\hline 49 & Paraba do Sul & 37410 & 41088 & 0,94 \\
\hline 50 & Cordeiro & 18601 & 20403 & 0,93 \\
\hline 51 & Vassouras & 31451 & 34439 & 0,91 \\
\hline 52 & São José de Ubá & 6413 & 7003 & 0,88 \\
\hline 53 & Engenheiro Paulo de Frontin & 12164 & 13239 & 0,85 \\
\hline 54 & Valença & 66308 & 71894 & 0,81 \\
\hline 55 & Belford Roxo & 434474 & 469261 & 0,77 \\
\hline 56 & Rio de Janeiro & 5857904 & 6323037 & 0,77 \\
\hline 57 & Macuco & 4886 & 5269 & 0,76 \\
\hline 58 & Três Rios & 71976 & 77503 & 0,74 \\
\hline 59 & Rio Claro & 16228 & 17401 & 0,70 \\
\hline 60 & Barra do Piraí & 88503 & 94855 & 0,70 \\
\hline 61 & Volta Redonda & 242063 & 257996 & 0,64 \\
\hline 62 & Niterói & 459451 & 487327 & 0,59 \\
\hline 63 & São Sebastião do Alto & 8402 & 8906 & 0,58 \\
\hline 64 & Paty do Alferes & 24931 & 26381 & 0,57 \\
\hline 65 & Duas Barras & 10334 & 10933 & 0,57 \\
\hline 66 & Sumidouro & 14176 & 14920 & 0,51 \\
\hline 67 & Bom Jesus do Itabapoana & 33655 & 35384 & 0,50 \\
\hline 68 & São José do Vale do Rio Preto & 19278 & 20252 & 0,49 \\
\hline
\end{tabular}

Geo UERJ - Ano 14, no. 23, v. 1, $1^{\circ}$ semestre de 2012 p. 262-301

ISSN: 1415-7543 E-ISSN: 1981-9021

http://www.e-publicacoes.uerj.br/index.php/geouerj 


\begin{tabular}{|c|c|c|c|c|}
\hline 69 & Nova Friburgo & 173418 & 182016 & 0,49 \\
\hline 70 & Santo Antônio de Pádua & 38692 & 40569 & 0,47 \\
\hline 71 & Barra Mansa & 170753 & 177861 & 0,41 \\
\hline 72 & Mendes & 17289 & 17940 & 0,37 \\
\hline 73 & Petrópolis & 286537 & 296044 & 0,33 \\
\hline 74 & Comendador Levy Gasparian & 7924 & 8183 & 0,32 \\
\hline 75 & Mesquita & 167272 & 168403 & 0,31 \\
\hline 76 & Miguel Pereira & 23902 & 24647 & 0,31 \\
\hline 77 & Nilópolis & 153712 & 157483 & 0,24 \\
\hline 78 & Trajano de Morais & 10038 & 10281 & 0,24 \\
\hline 79 & São João de Meriti & 449476 & 459356 & 0,22 \\
\hline 80 & São Fidélis & 36789 & 37553 & 0,21 \\
\hline 81 & Sapucaia & 17157 & 17504 & 0,20 \\
\hline 82 & Cambuci & 14670 & 14829 & 0,11 \\
\hline 83 & São Francisco de Itabapoana & 41145 & 41357 & 0,05 \\
\hline 84 & Silva Jardim & 21265 & 21360 & 0,04 \\
\hline 85 & Cantagalo & 19835 & 19826 & 0,00 \\
\hline 86 & Natividade & 15125 & 15077 & $-0,03$ \\
\hline 87 & Cardoso Moreira & 12595 & 12540 & $-0,04$ \\
\hline 88 & Itaocara & 23003 & 22902 & $-0,04$ \\
\hline 89 & Miracema & 27064 & 26829 & $-0,09$ \\
\hline 90 & Santa Maria Madalena & 10476 & 10321 & $-0,15$ \\
\hline 91 & Laje do Muriaé & 7909 & 7491 & $-0,54$ \\
\hline 92 & Nova Iguaçu & 753327 & 795212 & $-1,45$ \\
\hline
\end{tabular}

Fonte: IBGE - Censo Demográfico 2000 e 2010

Deste total, 11 municípios estão localizados na Periferia Metropolitana, 11 nas Baixadas Litorâneas, 7 no Norte Fluminense e 10 no Sul Fluminense.

Tais resultados, em parte são explicados pela própria expansão da metrópole, no qual podemos destacar Maricá com 5,21\% a.a. e Mangaratiba com 3,84\% a.a., como também, alicerçados pelo aquecimento da economia desses municípios, tendo como resultado taxas de crescimento expressivas, e destas, Rio das Ostras registrou 11,25\% a.a. sendo considerada a mais elevada taxa do país, em decorrência do forte movimento populacional, impulsionado pelas atividades de extração de petróleo no litoral do 
estado, e que se dirige para este município a procura de moradias mais acessíveis que em Macaé. O mesmo fato verifica-se em Casimiro de Abreu que registrou 4,79\% a.a., representado pelo distrito de Barra de São João recebendo contingente populacional. Tais municípios funcionam como verdadeiros núcleos residenciais de Macaé, no qual o mercado imobiliário é extremamente aquecido tanto para compra como para aluguel de moradias.

Observando a referida tabela, além dos quatro municípios já mencionados, seis registram taxas de crescimento superior a 3,84\% a.a., todos localizados em duas regiões liteorâneas extremamente dinâmicas no estado, as Baixadas Litorâneas e o Norte Fluminense, nas quais os royalties do petróleo (MORAIS, 2010), os serviços atrelados as atividades de lazer - turismo e segunda residência (RIBEIRO; COELHO, 2008), tem provocado aumento populacional expressivo nas três últimas décadas conforme indicado na tabela 4, na qual também estão incluídas as taxas geométricas do período 1991-2000, para efeito comparatvo.

Tabela 4 - Estado do Rio de Janeiro: Maiores Municípios segundo Taxa Geométrica de Crescimento 2000 - 2010 / 1991 - 2000 (\%

a.a.)

\begin{tabular}{|c|c|c|}
\hline Município & $\mathbf{2 0 0 0} \mathbf{- 2 0 1 0}$ & $\mathbf{1 9 9 1} \mathbf{2 0 0 0}$ \\
\hline 1. Rio das Ostras & 11,25 & 6,95 \\
\hline 2. Maricá & 5,21 & 6,16 \\
\hline 3. Casimiro de Abreu & 4,79 & 3,88 \\
\hline 4. Macaé & 4,55 & - \\
\hline 5. Carapebus & 4,41 & 6,08 \\
\hline 6. Iguaba Grande & 4,24 & - \\
\hline 7. Armação dos Búzios & 4,23 & 5,77 \\
\hline 8. Quissamã & 4,00 & 537 \\
\hline 9. Cabo Frio & 3,92 & - \\
\hline 10. Mangaratiba & 3,84 & -57 \\
\hline
\end{tabular}

Fonte: IBGE - Censo Demográfico 1991, 2000 e 2010 
Espacialmente podemos observar dois eixos expressivos de crescimento no estado do Rio de Janeiro (mapa 2): o primeiro, apresentando as taxas mais elevadas, parte de Maricá, na Região Metropolitana, passa por municípios das Baixadas Litorâneas, atingindo o município de Quissamã, na Região Norte Fluminense; o segundo eixo estende-se pelo litoral sul Fluminense deslocando-se de Itaguaí, na Região Metropolitana e adentrando a partir de Mangaratiba pela Região da Costa Verde, atingindo Parati. Estes dois segmentos bem marcados, são cortados pelas rodovias BR101, no sentido sul-norte, e pela RJ-106, mais próxima ao litoral, na porção norte do estado. Graças a estes sistemas de engenharia, a partir de meados dos anos 1970 o processo de expansão populacional nestas áreas foi intensificando-se, permitindo articulações entre a metrópole do Rio de Janeiro com estas porções litorâneas do estado, no qual, como já mencionado, predominam as atividades de lazer, vinculadas ao turismo e a segunda residência, e atualmente incrementadas também pelos recursos procedentes dos royalties do petróleo.

Mapa 2: Taxa Geométrica de Crescimento 2000 - 2010 (\% a.a.)

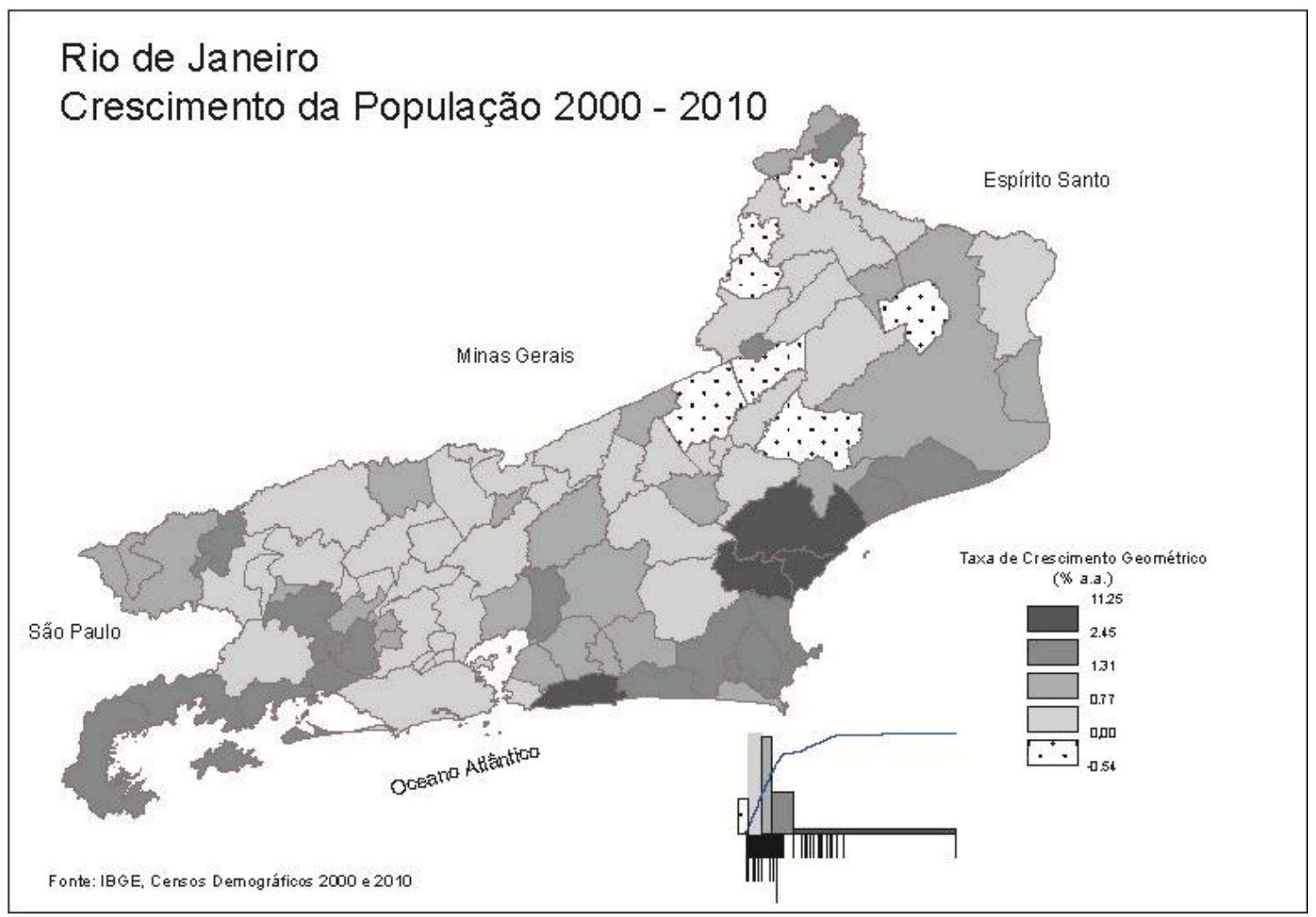

Geo UERJ - Ano 14, no. 23, v. 1, $1^{\circ}$ semestre de 2012 p. 262-301

ISSN: 1415-7543 E-ISSN: 1981-9021

http://www.e-publicacoes.uerj.br/index.php/geouerj 
Por outro lado, 49 municípios fluminenses acusaram taxas geométricas de crescimento inferiores a média estadual, como pode ser observado na tabela 3 . Deste total, quinze municípios apresentaram valores inferiores a 0,25\% a.a. (tabela 5), e destes. sete registraram valores negativos, que em alguns casos representam perda de população, em decorrência de desmembramento municipal, exemplificado com Nova Iguaçu, que acusou a menor taxa para o estado, em função da perda do distrito de Mesquita em 1992, fato registrado quando observamos os resultados referentes a taxa geométrica de crescimento 2000-2010. Os demais municípios com taxas geométricas negativas são aqueles que apresentam pouco dinamismo economico, localizados principalmente nas regiões Noroeste, Norte e Serrana fluminenses, no qual são verdadeiros dispersores de população para outras localidades. Para aqueles municípios localizados no Noroeste fluminense, este fato vem ratificando-se há mais de 50 anos, com perda gradativa da população, podendo-se tomar como exemplo o município de Santa Maria Madalena, em que as taxas de crescimento diminuiram ao longo dos períodos censitários, -1,16 entre 1970 e 1980, -0,19 entre 1980 e 1991, -0,39 entre 1991 e 2000 e $-0,15$ no intervalo mais recente.

Tabela 5 - Estado do Rio de Janeiro: Menores Municípios segundo Taxa

Geométrica de Crescimento 2000 - 2010 / 1991 - 2000 (\% a.a.)

\begin{tabular}{|c|c|c|}
\hline Município & $\mathbf{2 0 0 0} \mathbf{- 2 0 1 0}$ & $\mathbf{1 9 9 1} \mathbf{- 2 0 0 0}$ \\
\hline 1. Nova Iguaçu & $-1,45$ & 2,60 \\
\hline 2. Laje do Muriaé & $-0,54$ & $-1,18$ \\
\hline 3. Santa Maria Madalena & $-0,15$ & - \\
\hline 4. Miracema & $-0,09$ & $-0,30$ \\
\hline 5. Itaocara & $-0,04$ & $-0,01$ \\
\hline 6. Cardoso Moreira & $-0,04$ & - \\
\hline 7. Natividade & $-0,03$ & - \\
\hline 8. Cantagalo & 0,00 & 3,47 \\
\hline 9. Silva Jardim & 0,04 & $-0,46$ \\
\hline 10. São Francisco de Itabapoana & 0,05 & - \\
\hline 11. Cambuci & 0,11 & - \\
\hline 12. Sapucaia & 0,20 & 0,21 \\
\hline 13. São Fidélis & & \\
\hline
\end{tabular}

Geo UERJ - Ano 14, n. 23, v. 1, $1^{\circ}$ semestre de 2012 p. 262-301 ISSN: 1415-7543 E-ISSN: 1981-9021 http://www.e-publicacoes.uerj.br/index.php/geouerj 


\begin{tabular}{|l|c|c|} 
14. São João de Meriti & 0,22 & 0,87 \\
\hline 15. Trajano de Morais & 0,24 & $-1,36$ \\
\hline
\end{tabular}

Fonte: IBGE - Censo Demográfico 1991, 2000 e 2010

A taxa geométrica de crescimento tem correspondência com a localização do domicílio, situação que pode ser urbana ou rural, definida por lei municipal em vigor em 01/08/2010. Este fato é que será tratado na próxima seção.

\section{Domínio do Urbano sobre o Rural no Território Fluminense}

Outra característica demográfica importante diz respeito ao território fluminense apresentar um domínio da população residente urbana sobre a população rural, ou seja, registra a mais elevada taxa de população urbana do país, sendo que mais de 96,6\% de seus residentes vivem em cidades e vilas ${ }^{5}$.

Tabela 6 - Estado do Rio de Janeiro: População Residente por Situação do Domicílio nas Datas dos Recenseamentos 1960/2010

\begin{tabular}{|c|c|c|c|c|c|}
\hline \multirow{2}{*}{$\begin{array}{c}\text { Data dos Recenseamentos } \\
\text { Gerais }\end{array}$} & \multicolumn{5}{|c|}{ Situação do Domicílio } \\
\cline { 2 - 6 } & Total & Urbana & $\%$ & Rural & $\%$ \\
\hline $01 / 09 / 1960$ & 6.610 .748 & 5.214 .809 & 78,9 & 1.395 .939 & 21,1 \\
\hline $01 / 09 / 1970$ & 8.996 .722 & 7.906 .146 & 87,9 & 1.088 .656 & 12,1 \\
\hline $01 / 09 / 1980$ & 11.293 .611 & 10.368 .191 & 91,8 & 923.329 & 8,1 \\
\hline $01 / 09 / 1991$ & 12.802 .697 & 12.199 .641 & 95,3 & 608.065 & 4,7 \\
\hline $01 / 08 / 2000$ & 14.393 .282 & 13.683 .859 & 95,1 & 430.804 & 3,0 \\
\hline $01 / 08 / 2010$ & 15.993 .583 & 15.446 .996 & 96,6 & 526.587 & 3,3 \\
\hline
\end{tabular}

Fonte: IBGE - Censo Demográfico 1960, 1970, 1980, 1991, 2000 e 2010

Gráfico 1: Evolução da População do Rio de Janeiro 1950-2010 


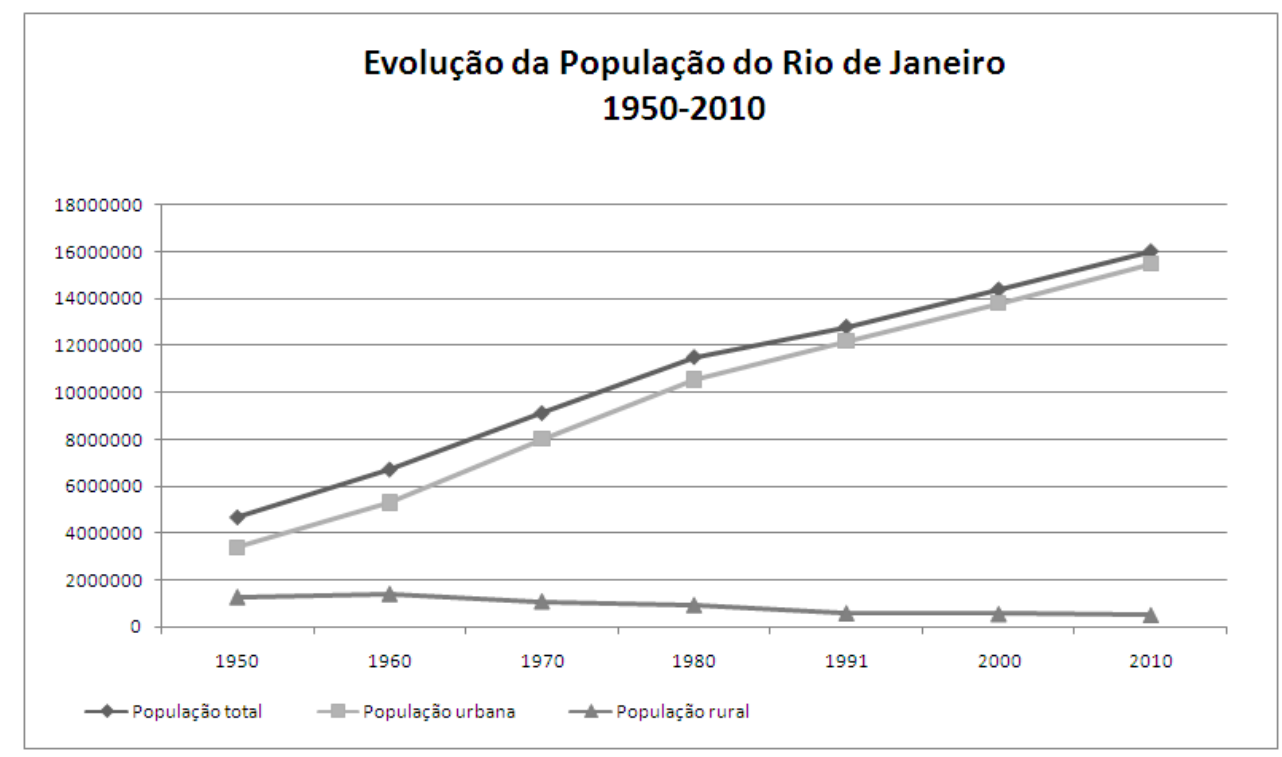

Fonte: IBGE - Censo Demográfico 1950, 1960, 1970, 1980, 1991, 2000 e 2010

Confrontando os recenseamentos gerais de 1960 a 2010, conforme indicados na tabela 6 e no gráfico 1, pode-se verificar tal situação, de modo generalizado para o estado, sendo que no Rio de Janeiro a população urbana superou a população rural antes da metade do século XX, na década de 1940, enquanto que somente na década de 1970 o país atingiu este ponto de inflexão. Atualmente, com esta progressiva diminuição, a população rural no Rio de Janeiro corresponde a apenas 3,3\% da população residente total. À guisa de comparação, enquanto o Brasil registrava $18,7 \%$ da população vivendo em áreas rurais para o ano 2000, o estado do Rio de Janeiro acusava 4,0\%, em 2010 este valor cai para $15,6 \%$ e $3,3 \%$, respectivamente.

Pode-se aferir que o crescimento da população urbana no país ocorre a partir de 1960, e principalmente acelera na década de 1970, sendo este período marcado pela "explosão do crescimento urbano", com o processo de concentração da população em cidades cada vez maiores (MARTINE, 1987), atrelado a um processo de industrialização desencadeado sobretudo nas metrópoles. Portanto, pode-se concluir que o estado do Rio de Janeiro desde os anos de 1940 apresentou crescimento urbano superior ao nacional. 
Na tabela 6 podemos observar que a partir de 1960 a população residente em área rural fluminense começa a declinar de forma vertiginosa, acompanhando a própria tendência nacional, como pode ser verificado na pesquisa de Baeninger (s/d).

Analisando a taxa geométrica anual para os dois últimos períodos censitários (01/08/2000 e 01/08/2010), conforme indicado na tabela 7, a população urbana acusou $0,30 \%$ a.a., enquanto a população rural registrou $-1,62 \%$ a.a. Estes resultados são inferiores aqueles registrados para o período 1991-2000, no qual a população vivendo em áreas urbanas foi de $1,39 \%$ a.a. contra $-0,74 \%$ a.a. para aqueles residindo em áreas rurais.

Tabela 7 - Estado do Rio de Janeiro: Taxa Média Geométrica de Crescimento Anual (\% a.a.) - 1960 - 2010

\begin{tabular}{|c|c|c|c|}
\hline \multirow{2}{*}{$\begin{array}{c}\text { Data dos Recenseamentos } \\
\text { Gerais }\end{array}$} & \multicolumn{3}{|c|}{ Situação do Domicílio } \\
\hline & Total & Urbana & Rural \\
\hline De 01/09/1960 a 01/09/1970 & 3,13 & 4,25 & $-2,46$ \\
\hline De 01/09/1970 a 01/09/1980 & 2,30 & 2,75 & $-1,63$ \\
\hline De 01/09/1980 a 01/09/1991 & 1,15 & 1,49 & $-3,73$ \\
\hline De 01/09/1991 a 01/09/2000 & 1,30 & 1,39 & $-0,74$ \\
\hline De 01/09/2000 a 01/09/2010 & 1,05 & 0,30 & $-1,62$ \\
\hline
\end{tabular}

Fonte: IBGE - Censo Demográfico 1960, 1970, 1980, 1991, 2000 e 2010

Esse incremento vertiginoso da população fluminense residindo em áreas urbanas, e acompanhando a tendência nacional, foi consequência, basicamente, de três fatores: do próprio crescimento vegetativo das áreas urbanas; da migração com destino urbano; e da expansão pelas prefeituras do perímetro urbano de muitas localidades, antigamente consideradas rurais, fato atrelado ao recolhimento do imposto territorial urbano (IPTU) que é recolhido na esfera municipal, diferente do imposto territorial rural (ITR) que é recolhido na esfera federal, dependendo de repasses para as prefeituras.

Em contrapartida a esta tendência do incremento da população urbana, a população que reside em áreas consideradas rurais vem apresentando participação cada vez menor de seus residentes no território fluminense, acompanhando a própria 
tendência da distribuição da população residente no país. Baeninger (s/d, p. 274) aponta que a taxa de crescimento da população rural nos anos 1970 e nos anos 1980 alcançou taxas negativas, em torno de $0,60 \%$ a.a. Segundo a autora, “em 1980, aliás, a população rural brasileira registrou pela primeira vez na história deste século diminuição em números absolutos; em 2000, sua taxa de crescimento alcançou -1,3\% a.a.”.

$\mathrm{Na}$ tabela 8 estão indicados para os 92 municípios fluminenses o grau de urbanização segundo o Censo Demográfico 2010, além de registrar os totais da população urbana e da população rural. Deste conjunto somente quatro municípios apresentam grau de urbanização inferior a 50,0\% e seis apresentam de 50,9\% a 64,3\% (tabela 9). Este conjunto de 10 municípios localizado nas regiões Serrana, Noroeste e Norte Fluminenses tem suas economias voltadas para as atividades agropecuárias, apresentando em relação ao estado percentuais de urbanização pouco expressivos.

Tabela 8 - Estado do Rio de Janeiro: Grau de Urbanização 2010

\begin{tabular}{|c|c|c|c|c|}
\hline Município & Total População & $\begin{array}{c}\text { Total População } \\
\text { Urbana }\end{array}$ & $\begin{array}{c}\text { Total População } \\
\text { Rural }\end{array}$ & $\begin{array}{c}\text { Grau de } \\
\text { urbanização }(\%)\end{array}$ \\
\hline Rio de Janeiro & 6323037 & 6323037 & 0 & 100,00 \\
\hline Niterói & 487327 & 487327 & 0 & 100,00 \\
\hline Belford Roxo & 469261 & 469261 & 0 & 100,00 \\
\hline São João de Meriti & 459356 & 459356 & 0 & 100,00 \\
\hline Mesquita & 168403 & 168403 & 0 & 100,00 \\
\hline Nilópolis & 157483 & 157483 & 0 & 100,00 \\
\hline Queimados & 137938 & 137938 & 0 & 100,00 \\
\hline Japeri & 95391 & 95391 & 0 & 100,00 \\
\hline Arraial do Cabo & 27770 & 27770 & 0 & 100,00 \\
\hline Armação dos B·zios & 27538 & 27538 & 0 & 100,00 \\
\hline Iguaba Grande & 22858 & 22858 & 0 & 100,00 \\
\hline Volta Redonda & 257996 & 257879 & 117 & 99,95 \\
\hline São Gonçalo & 999901 & 999161 & 740 & 99,93 \\
\hline Duque de Caxias & 855046 & 852131 & 2915 & 99,66 \\
\hline Porto Real & 16574 & 16481 & 93 & 99,44 \\
\hline Barra Mansa & 177861 & 176251 & 1610 & 99,09 \\
\hline Nova Iguaçu & 795212 & 786536 & 8676 & 98,91 \\
\hline Itaboraí & 218090 & 215503 & 2587 & 98,81 \\
\hline Mendes & 17940 & 17706 & 234 & 98,70 \\
\hline
\end{tabular}

Geo UERJ - Ano 14, n. 23, v. 1, $1^{\circ}$ semestre de 2012 p. 262-301

ISSN: 1415-7543 E-ISSN: 1981-9021

http://www.e-publicacoes.uerj.br/index.php/geouerj 


\begin{tabular}{|c|c|c|c|c|}
\hline Maricá & 127519 & 125532 & 1987 & 98,44 \\
\hline Macaé & 206748 & 202873 & 3875 & 98,13 \\
\hline Cordeiro & 20403 & 19835 & 568 & 97,22 \\
\hline Três Rios & 77503 & 75233 & 2270 & 97,07 \\
\hline Barra do Piraí & 94855 & 92040 & 2815 & 97,03 \\
\hline Guapimirim & 51487 & 49757 & 1730 & 96,64 \\
\hline Itatiaia & 28852 & 27848 & 1004 & 96,52 \\
\hline Angra dos Reis & 169270 & 163080 & 6190 & 96,34 \\
\hline Comendador Levy Gasparian & 8183 & 7865 & 318 & 96,11 \\
\hline Itaguaí & 109163 & 104292 & 4871 & 95,54 \\
\hline Araruama & 112028 & 106519 & 5509 & 95,08 \\
\hline Petrópolis & 296044 & 281356 & 14688 & 95,04 \\
\hline Saquarema & 74221 & 70448 & 3773 & 94,92 \\
\hline Magé & 228150 & 215941 & 12209 & 94,65 \\
\hline Rio das Ostras & 105757 & 99999 & 5758 & 94,56 \\
\hline Quatis & 12831 & 12067 & 764 & 94,05 \\
\hline Resende & 119801 & 112375 & 7426 & 93,80 \\
\hline São Pedro da Aldeia & 88013 & 82286 & 5727 & 93,49 \\
\hline Itaperuna & 95876 & 88408 & 7468 & 92,21 \\
\hline Miracema & 26829 & 24701 & 2128 & 92,07 \\
\hline Campos dos Goytacazes & 463545 & 418565 & 44980 & 90,30 \\
\hline Pinheiral & 22724 & 20414 & 2310 & 89,83 \\
\hline Tanguá & 30731 & 27426 & 3305 & 89,25 \\
\hline Teresópolis & 163805 & 145473 & 18332 & 88,81 \\
\hline Paracambi & 47074 & 41677 & 5397 & 88,54 \\
\hline Mangaratiba & 36311 & 31989 & 4322 & 88,10 \\
\hline Paraíba do Sul & 41088 & 36159 & 4929 & 88,00 \\
\hline Nova Friburgo & 182016 & 159335 & 22681 & 87,54 \\
\hline Miguel Pereira & 24647 & 21508 & 3139 & 87,26 \\
\hline Macuco & 5269 & 4593 & 676 & 87,17 \\
\hline Aperibé & 10215 & 8880 & 1335 & 86,93 \\
\hline Areal & 11421 & 9920 & 1501 & 86,86 \\
\hline Valença & 71894 & 62266 & 9628 & 86,61 \\
\hline Cachoeiras de Macacu & 54370 & 47015 & 7355 & 86,47 \\
\hline Conceição de Macabu & 21200 & 18332 & 2868 & 86,47 \\
\hline Bom Jesus do Itabapoana & 35384 & 29912 & 5472 & 84,54 \\
\hline Seropédica & 78183 & 64297 & 13886 & 82,24 \\
\hline Casimiro de Abreu & 35373 & 28533 & 6840 & 80,66 \\
\hline Natividade & 15077 & 12041 & 3036 & 79,86 \\
\hline
\end{tabular}

Geo UERJ - Ano 14, no. 23, v. 1, $1^{\circ}$ semestre de 2012 p. 262-301

ISSN: 1415-7543 E-ISSN: 1981-9021

http://www.e-publicacoes.uerj.br/index.php/geouerj 


\begin{tabular}{|c|c|c|c|c|}
\hline Piraí & 26309 & 20831 & 5478 & 79,18 \\
\hline São Fidélis & 37553 & 29689 & 7864 & 79,06 \\
\hline Rio Claro & 17401 & 13754 & 3647 & 79,04 \\
\hline Carapebus & 13348 & 10542 & 2806 & 78,98 \\
\hline São João da Barra & 32767 & 25715 & 7052 & 78,48 \\
\hline Porci·ncula & 17771 & 13902 & 3869 & 78,23 \\
\hline Carmo & 17439 & 13474 & 3965 & 77,26 \\
\hline Santo Antônio de Pádua & 40569 & 31086 & 9483 & 76,63 \\
\hline Cambuci & 14829 & 11301 & 3528 & 76,21 \\
\hline Sapucaia & 17504 & 13247 & 4257 & 75,68 \\
\hline Itaocara & 22902 & 17329 & 5573 & 75,67 \\
\hline Silva Jardim & 21360 & 16126 & 5234 & 75,50 \\
\hline Cabo Frio & 186222 & 140466 & 45756 & 75,43 \\
\hline Laje do Muriaé & 7491 & 5636 & 1855 & 75,24 \\
\hline Rio Bonito & 55586 & 41267 & 14319 & 74,24 \\
\hline Parati & 37575 & 27717 & 9858 & 73,76 \\
\hline Italva & 14027 & 10228 & 3799 & 72,92 \\
\hline Engenheiro Paulo de Frontin & 13239 & 9525 & 3714 & 71,95 \\
\hline Duas Barras & 10933 & 7739 & 3194 & 70,79 \\
\hline Cantagalo & 19826 & 14027 & 5799 & 70,75 \\
\hline Paty do Alferes & 26381 & 18607 & 7774 & 70,53 \\
\hline Cardoso Moreira & 12540 & 8764 & 3776 & 69,89 \\
\hline Rio das Flores & 8545 & 5948 & 2597 & 69,61 \\
\hline Vassouras & 34439 & 23192 & 11247 & 67,34 \\
\hline Quissamã & 20244 & 13016 & 7228 & 64,30 \\
\hline Varre-Sai & 9503 & 5805 & 3698 & 61,09 \\
\hline Bom Jardim & 25398 & 15281 & 10117 & 60,17 \\
\hline Santa Maria Madalena & 10321 & 5932 & 4389 & 57,48 \\
\hline São Sebastião do Alto & 8906 & 4623 & 4283 & 51,91 \\
\hline São Francisco de Itabapoana & 41357 & 21090 & 20267 & 50,99 \\
\hline Trajano de Morais & 10281 & 4776 & 5505 & 46,45 \\
\hline São José do Vale do Rio Preto & 20252 & 9005 & 11247 & 44,46 \\
\hline São José de Ubá & 7003 & 3098 & 3905 & 44,24 \\
\hline Sumidouro & 14920 & 5458 & 9462 & 36,58 \\
\hline Estado Rio de Janeiro & 15993583 & 15466996 & 526587 & $96,71 \%$ \\
\hline
\end{tabular}

Fonte: IBGE - Censo Demográfico 2010

Geo UERJ - Ano 14, nº 23 , v. 1, $1^{\circ}$ semestre de 2012 p. 262-301

ISSN: 1415-7543 E-ISSN: 1981-9021

http://www.e-publicacoes.uerj.br/index.php/geouerj 
Tabela 9 - Estado do Rio de Janeiro:

Municípios com Menor Grau de Urbanização

2010

\begin{tabular}{|c|c|}
\hline Município & $\begin{array}{c}\text { Grau de } \\
\text { urbanização (\%) }\end{array}$ \\
\hline Quissamã & 64,30 \\
\hline Varre-Sai & 61,09 \\
\hline Bom Jardim & 60,17 \\
\hline Santa Maria Madalena & 57,48 \\
\hline São Sebastião do Alto & 51,91 \\
\hline São Francisco de Itabapoana & 50,99 \\
\hline Trajano de Morais & 46,45 \\
\hline São José do Vale do Rio Preto & 44,46 \\
\hline São José de Ubá & 44,24 \\
\hline Sumidouro & 36,58 \\
\hline
\end{tabular}

Fonte: IBGE - Censo Demográfico 2010

Do total da população urbana estadual (tabela 10), correspondendo a 14.106.423 residentes, 83,5\% encontra-se na Região Metropolitana, sendo que 44,8\% no núcleo (cidade do Rio de Janeiro), contra 16,5\% distribuida pelo interior, manifestando o caráter concentrador da distribuição dos residentes em cidades e vilas nos limites metropolitanos. Somente a cidade do Rio de Janeiro concentra $44,8 \%$ da população urbana estadual, fato ainda bastante expressivo diante dos demais municípios.

Tabela 10 - Estado do Rio de Janeiro: Distribuição da População Urbana e Rural, Variação Relativa e Taxa Geométrica de Crescimento (\% a.a.) 2000 - 2010

\begin{tabular}{|c|c|c|c|c|}
\hline $\begin{array}{c}\text { Estado, Região } \\
\text { Metropolitana e Interior }\end{array}$ & $\begin{array}{c}\text { População } \\
\text { Urbana 2000 }\end{array}$ & $\begin{array}{c}\text { População } \\
\text { Urbana 2010 }\end{array}$ & $\begin{array}{c}\text { Variação Relativa } \\
(\mathbf{\% )} \mathbf{2 0 1 0}\end{array}$ & $\begin{array}{c}\text { Taxa de } \\
\text { Crescimento }\end{array}$ \\
\hline Núcleo & 5.851 .914 & 6.320 .446 & 44,8 & 0,77 \\
\hline Periferia & 4.920 .779 & 5.457 .051 & 38,7 & 1,04 \\
\hline Região Metropolitana & 10.772 .693 & 11.777 .497 & 83,5 & 0,90 \\
\hline Interior & 2.911 .166 & 2.328 .926 & 16,5 & $-2,21$ \\
\hline Estado do Rio de Janeiro & 13.683 .859 & 14.106 .423 & 100,0 & 0,30 \\
\hline
\end{tabular}

Geo UERJ - Ano 14, no. 23, v. 1, $1^{\circ}$ semestre de 2012 p. 262-301

ISSN: 1415-7543 E-ISSN: 1981-9021

http://www.e-publicacoes.uerj.br/index.php/geouerj 


\begin{tabular}{|c|c|c|c|c|}
$\begin{array}{c}\text { Estado, Região } \\
\text { Metropolitana e Interior }\end{array}$ & $\begin{array}{c}\text { População } \\
\text { Rural 2000 }\end{array}$ & $\begin{array}{c}\text { População } \\
\text { Rural 2010 }\end{array}$ & $\begin{array}{c}\text { Variação Relativa } \\
(\mathbf{\% )} \mathbf{2 0 1 0}\end{array}$ & $\begin{array}{c}\text { Taxa de } \\
\text { Crescimento }\end{array}$ \\
\hline Núcleo & 0 & 0 & 0 & 0,00 \\
\hline Periferia & 75.221 & 58.211 & 15,9 & $-2,53$ \\
\hline Região Metropolitana & 75.221 & 58.211 & 15,9 & $-2,53$ \\
\hline Interior & 355.583 & 307.722 & 84,1 & $-1,44$ \\
\hline Estado do Rio de Janeiro & 430.804 & 365.933 & 100,0 & $-1,62$ \\
\hline
\end{tabular}

Fonte: IBGE - Censo Demográfico 2000 e 2010

Estas informações censitárias podem ser explicadas em função das maiores cidades fluminenses em tamanho populacional estarem nos limites metropolitanos, conforme pode ser comprovado na tabela 11. Nestas circunstâncias, 11 cidades acusaram para 2010 população residente superior a 100 mil habitantes, portanto, consideradas cidades de médio porte para o padrão nacional.

Tabela 11 - Estado do Rio de Janeiro: Maiores

Sedes Municipais (cidades) com População

Superior a 95 Mil Habitantes - 2010

\begin{tabular}{|c|c|c|}
\hline & Sede Municipal & População Residente \\
\hline 1 & Rio de Janeiro & 6320446 \\
\hline 2 & Nova Iguaçu & 787563 \\
\hline 3 & Niterói & 487562 \\
\hline 4 & Belford Roxo & 469332 \\
\hline 5 & Campos dos Goytacazes & 356608 \\
\hline 6 & Duque de Caxias & 341304 \\
\hline 7 & São Gonçalo & 337273 \\
\hline 8 & Volta Redonda & 257686 \\
\hline 9 & São João de Meriti & 234389 \\
\hline 10 & Macaé & 194711 \\
\hline 11 & Petrópolis & 185876 \\
\hline 12 & Barra Mansa & 171405 \\
\hline 13 & Mesquita & 168376 \\
\hline 14 & Cabo Frio & 140269 \\
\hline 15 & Queimados & 137962 \\
\hline 16 & Teresópolis & 134045 \\
\hline
\end{tabular}

Geo UERJ - Ano 14, no. 23, v. 1, $1^{\circ}$ semestre de 2012 p. 262-301

ISSN: 1415-7543 E-ISSN: 1981-9021

http://www.e-publicacoes.uerj.br/index.php/geouerj 


\begin{tabular}{l|c|c|}
\hline 17 & Nova Friburgo & 113108 \\
\cline { 2 - 3 } 18 & Itaboraí & 107117 \\
\cline { 2 - 3 } 19 & Itaguaí & 104156 \\
\cline { 2 - 3 } 20 & Nilópolis & 101968 \\
\cline { 2 - 3 } 21 & Rio das Ostras & 99905 \\
\cline { 2 - 3 } 22 & Japeri & 95492 \\
\hline
\end{tabular}

Fonte: IBGE - Censo Demográfico 2010

Quanto às cidades localizadas no interior fluminense, pode-se afirmar que são pouco representativas do ponto de vista do tamanho populacional, caracterizadas por aquelas de pequeno porte, sendo que de um total de 73 sedes municipais, 51 registram população residente inferior a 25 mil habitantes, segundo o Censo Demográfico 2010, sendo que deste total, 21 acusam populaçâo residente inferior a 10 mil habitantes. Por outro lado, 9 cidades estão alocadas no patamar entre 100 mil a 360 mil residentes, consideradas cidades médias, não somente pelo tamanho populacional, mas também pelas relações economicas, e na oferta de bens e serviços que estabelecem com outros municípios que configuram sua área de influência (SANTOS, 2003).

O conjunto das 22 sedes municipais (cidades) com população superior a 95 mil residentes, representam $73,3 \%$ da população urbana total, sendo que aproximadamente $62,7 \%$ encontram-se residindo nos limites da metrópole, correspondendo a 9.692 .940 habitantes, contra apenas 10,7\% localizadas no interior, acusando um total de 1.653 .613 residentes.

No mapa 3 estão representadas as sedes municipais que registraram população residente maior que 50 mil habitantes, ratificando o papel concentrador metropolitano diante de um interior pouco representativo.

Mapa 3: Rio de Janeiro - Maiores Sedes de Municípios de 2010 


\section{Rio de Janeiro}

Maiores Sedes de Municípios 2010

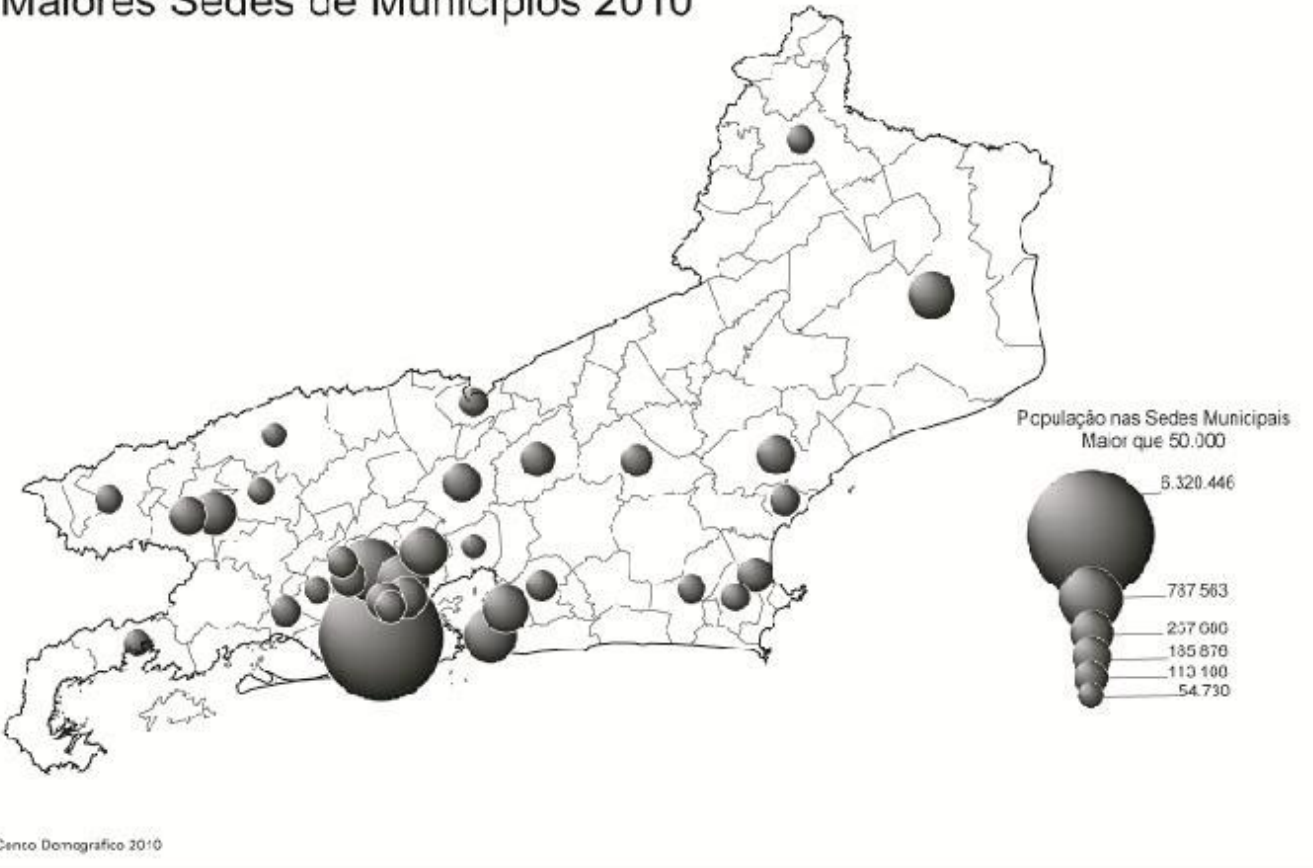

A urbanização tem sido o principal processo de organização do território fluminense, com aspectos de macrourbanização e metropolização, isto porque o aumento da população urbana no Estado foi mais significativo no núcleo e na periferia metropolitana entre 2000 e 2010, parte deste montante oriundo das áreas rurais. A crescente urbanização ocorreu com adensamento populacional em áreas já urbanizadas e incorporação de áreas rurais ao tecido urbano, em particular nos municípios de Itaguaí, Seropédica, Japeri e Queimados. Tanto o núcleo como a periferia da região metropolitana agregaram 500 mil habitantes, cada um, nos últimos dez anos reforçando a macrocefalia da metrópole fluminense.

O mapa 4 ilustra o crescimento das principais sedes de municípios com população maior de 50 mil habitantes, no período de 2000 a 2010, observa-se a desconcentração-concentrada que caracteriza aspectos da distribuição populacional do Estado. Na escala metropolitana, onde predomina forte concentração populacional, ocorre uma desconcentração à medida que alguns municípios já apresentam perda populacional. 
Nas outras regiões do Estado verifica-se a desconcentração na localização da população, uma vez que não são muitas as sedes com mais de 50 mil habitantes e poucas são as que apresentam dinamismo populacional. As regiões Litorâneas e Norte Fluminense registram forte crescimento de alguns de seus centros, impulsionados por fatores já mencionados.

Mapa 4: Rio de Janeiro - Tamanho e Crescimento Populacional 2000 - 2010

Rio de Janeiro

Tamanho e Crescimento Populacional $2000-2010$

Para o conjunto de cidades, localizadas no interior fluminense (tabela 11) chama atenção aquelas registrando expressiva concentração populacional associada a fatores histórico-economicos peculiares às suas respectivas regiões, exemplificadas por: Campos dos Goytacazes, em função da agroindústria açúcareira (CASTRO BARBOSA, 2003), das atividades de serviços educacionais (PIQUET; GIVISIEZ; OLIVEIRA; 2006 e PORTELLA, 2010) e serviços ligados à atividade petrolífera; Volta Redonda e Barra Mansa, situadas no Médio Vale do Paraíba do Sul, em decorrência da atividade industrial (CSN), e Petrópolis e Nova Friburgo, na Região Serrana, em razão da Geo UERJ - Ano 14, no. 23, v. 1, $1^{\circ}$ semestre de 2012 p. 262-301 
atividade industrial e dos serviços ligados à função de lazer (MARAFON; RIBEIRO, 2006); enquanto Macaé, Cabo Frio e Teresópolis, somente no final dos anos 1990, atingiram patamares superiores a 100 mil habitantes.

Tais resultados podem ser explicados pelas atividades da Petrobras instaladas em Macaé (RAMIRES, 1991; MORAIS, 2010), bem como aquelas vinculadas ao turismo, complementadas com aquelas provenientes do setor primário em Teresópolis; e Cabo Frio, com o turismo e segunda residência, contribuindo para o incremento na oferta de empregos no comércio e, principalmente no setor de serviços.

Complementando as ilustrações anteriores, a tabela 12 registra as 15 maiores vilas (sedes distritais) fluminenses com população superior a 50 mil habitantes para o ano 2010, em sua maioria localizadas nos limites metropolitanos, configurando um processo de conurbação das mesmas, com as cidades aí localizadas.

Tabela 12 - Estado do Rio de Janeiro: Maiores Sedes Distritais (vilas) com População Superior a 50 Mil Habitantes - 2010

\begin{tabular}{|c|c|c|}
\hline Distritos Sedes (vilas) & População Residente & Município \\
\hline Campos Elyseos & 290762 & Duque de Caxias \\
\hline Monjolo & 223058 & São Gonçalo \\
\hline Ipiíba & 193989 & São Gonçalo \\
\hline Coelho da Rocha & 167841 & São João de Meriti \\
\hline Neves & 161721 & São Gonçalo \\
\hline Imbariê & 161485 & Duque de Caxias \\
\hline Inhomirim & 109380 & Magé \\
\hline Sete Pontes & 82958 & São Gonçalo \\
\hline Inoã & 71484 & Maricá \\
\hline Cunhambebe & 69960 & Angra dos Reis \\
\hline Cascatinha & 64936 & Petrópolis \\
\hline Xerém & 58587 & Duque de Caxias \\
\hline Manilha & 58572 & Itaboraí \\
\hline São Mateus & 56443 & São João de Meriti \\
\hline Olinda & 55457 & Nilópolis \\
\hline
\end{tabular}

Fonte: IBGE - Censo Demográfico 2010 
Neste contexto, pode-se afirmar, mais uma vez, que o atual estado do Rio de Janeiro apresenta um perfil metropolitano de concentração populacional, marcado pelo adensamento populacional através da verticalização, mas também pela ampliação dos espaços urbanos através do processo de conurbação, apesar do interior fluminense, nos últimos 30 anos registrar alterações significativas, mesmo que pontuais, no quadro de suas cidades com mais de 100 mil habitantes, e no perfil da dinâmica demográfica fluminense.

O critério adotado para definir o urbano brasileiro, desde o primeiro Censo Demográfico oficial realizado pelo IBGE em 1940, vem sendo contestado por muitos estudiosos, entre eles Santos (1993), Limonad (1999) e Veiga (2000). Estes autores avaliam que o critério adotado pelo IBGE apresenta distorções, além de falsear os resultados, e, ainda, de haver a necessidade de fazer uma distinção entre cidade e urbano, conforme analisaram Ribeiro e Cavalcanti (2011). Cavalcanti, em 1999 elaborou uma Tipologia dos Municípios Brasileiros, procurando sanar tais distorções, e Ribeiro e O' Neill em 2011, a partir daquela autora (1999) elaboram uma tipologia para os municípios fluminenses. O’ Neill (2011) aponta a partir de Wanderley (2000) que

devido à complexidade e à diversificação das modernas formas de organização do território no meio rural, cada vez mais é necessário estabelecer critérios que demonstrem a existência de uma continuidade entre as duas concepções (ruralurbano), uma vez que a nova ruralidade não elimina o rural tradicional e a urbanização imprime seu ritmo de desenvolvimento ao campo (p. 1).

Para a tipologia foram utilizados três indicadores: da dimensão demográfica; do grau de urbanização; e do produto interno bruto (PIB), conforme indicado na tabela 13.

Tabela 13 - Tipologia dos Municípios Fluminenses

\begin{tabular}{|c|c|c|c|c|c|c|}
\hline & Municípios & $\begin{array}{c}\text { Total da população } \\
\text { (habitantes) }\end{array}$ & $\begin{array}{l}\text { Total da população } \\
\text { urbana habitantes }\end{array}$ & $\begin{array}{l}\text { População da sede } \\
\text { municipal (cidade) }\end{array}$ & $\begin{array}{c}\text { Grau de } \\
\text { urbanização }\end{array}$ & Tipol. \\
\hline 1 & Rio de Janeiro & 6320446 & 6320446 & 6320446 & 100,00 & 1 \\
\hline 2 & São Gonçalo & 999728 & 998999 & 337273 & 99,93 & 1 \\
\hline 3 & Duque de Caxias & 855048 & 852138 & 341304 & 99,66 & 3 \\
\hline
\end{tabular}

Geo UERJ - Ano 14, no. 23, v. 1, $1^{\circ}$ semestre de 2012 p. 262-301

ISSN: 1415-7543 E-ISSN: 1981-9021

http://www.e-publicacoes.uerj.br/index.php/geouerj 


\begin{tabular}{|c|c|c|c|c|c|c|}
\hline 4 & Nova Iguaçu & 796257 & 787563 & 787563 & 98,91 & 1 \\
\hline 5 & Niterói & 487562 & 487562 & 487562 & 100,00 & 1 \\
\hline 6 & Belford Roxo & 469332 & 469332 & 469332 & 100,00 & 2 \\
\hline 7 & Campos dos Goytacazes & 463731 & 418725 & 356608 & 90,29 & 5 \\
\hline 8 & São João de Meriti & 458673 & 458673 & 234389 & 100,00 & 1 \\
\hline 9 & Petrópolis & 295917 & 281286 & 185876 & 95,06 & 2 \\
\hline 10 & Volta Redonda & 257803 & 257686 & 257686 & 99,95 & 2 \\
\hline 11 & Magé & 227322 & 215236 & 54730 & 94,68 & 1 \\
\hline 12 & Itaboraí & 218008 & 215412 & 107117 & 98,81 & 1 \\
\hline 13 & Macaé & 206728 & 202859 & 194711 & 98,13 & 4 \\
\hline 14 & Cabo Frio & 186227 & 140486 & 140269 & 75,44 & 5 \\
\hline 15 & Nova Friburgo & 182082 & 159372 & 113108 & 87,53 & 1 \\
\hline 16 & Barra Mansa & 177813 & 176193 & 171371 & 99,09 & 2 \\
\hline 17 & Angra dos Reis & 169511 & 163290 & 66424 & 96,33 & 3 \\
\hline 18 & Mesquita & 168376 & 168376 & 168376 & 100,00 & 1 \\
\hline 19 & Teresópolis & 163746 & 146207 & 134045 & 89,29 & 1 \\
\hline 20 & Nilópolis & 157425 & 157425 & 101968 & 100,00 & 1 \\
\hline 21 & Queimados & 137962 & 137962 & 137962 & 100,00 & 2 \\
\hline 22 & Maricá & 127461 & 125491 & 40058 & 98,45 & 1 \\
\hline 23 & Resende & 119769 & 112331 & 77943 & 93,79 & 4 \\
\hline 24 & Araruama & 112008 & 106486 & 76073 & 95,07 & 1 \\
\hline 25 & Itaguaí & 109091 & 104209 & 104156 & 95,52 & 1 \\
\hline 26 & Rio das Ostras & 105676 & 99905 & 99905 & 94,54 & 5 \\
\hline 27 & Itaperuna & 95841 & 88368 & 77186 & 92,20 & 1 \\
\hline 28 & Japeri & 95492 & 95492 & 95492 & 100,00 & 1 \\
\hline 29 & Barra do Piraí & 94778 & 91957 & 69364 & 97,02 & 2 \\
\hline 30 & São Pedro da Aldeia & 87875 & 82148 & 82148 & 93,48 & 1 \\
\hline 31 & Seropédica & 78186 & 64285 & 62533 & 82,22 & 1 \\
\hline 32 & Três Rios & 77432 & 75165 & 73436 & 97,07 & 1 \\
\hline 33 & Saquarema & 74234 & 70456 & 26999 & 94,91 & 1 \\
\hline 34 & Valença & 71843 & 62224 & 55105 & 86,61 & 1 \\
\hline 35 & Rio Bonito & 55551 & 41259 & 32960 & 74,27 & 1 \\
\hline 36 & Cachoeiras de Macacu & 54273 & 46944 & 20365 & 86,50 & 2 \\
\hline 37 & Guapimirim & 51483 & 49746 & 49746 & 96,63 & 1 \\
\hline 38 & Paracambi & 47124 & 41722 & 41722 & 88,54 & 1 \\
\hline 39 & São F. de Itabapoana & 41354 & 21092 & 4444 & 51,00 & 1 \\
\hline 40 & Paraíba do Sul & 41084 & 36154 & 18078 & 88,00 & 1 \\
\hline 41 & Santo Antônio de Pádua & 40589 & 31100 & 22441 & 76,62 & 1 \\
\hline
\end{tabular}

Geo UERJ - Ano 14, nº. 23, v. 1, $1^{\circ}$ semestre de 2012 p. 262-301

ISSN: 1415-7543 E-ISSN: 1981-9021

http://www.e-publicacoes.uerj.br/index.php/geouerj 


\begin{tabular}{|c|c|c|c|c|c|c|}
\hline 42 & São Fidélis & 37543 & 29679 & 20939 & 79,05 & 6 \\
\hline 43 & Parati & 37533 & 27689 & 24337 & 73,77 & 2 \\
\hline 44 & Mangaratiba & 36456 & 32120 & 14419 & 88,11 & 1 \\
\hline 45 & B. Jesus do Itabapoana & 35411 & 29927 & 26654 & 84,51 & 1 \\
\hline 46 & Casimiro de Abreu & 35347 & 28521 & 16554 & 80,69 & 2 \\
\hline 47 & Vassouras & 34410 & 23199 & 21913 & 67,42 & 1 \\
\hline 48 & São João da Barra & 32747 & 25693 & 8356 & 78,46 & 6 \\
\hline 49 & Tanguá & 30732 & 27428 & 27428 & 89,25 & 1 \\
\hline 50 & Itatiaia & 28783 & 27813 & 20766 & 96,63 & 3 \\
\hline 51 & Arraial do Cabo & 27715 & 27715 & 27715 & 100,00 & 2 \\
\hline 52 & Armação dos Búzios & 27560 & 27560 & 27560 & 100,00 & 5 \\
\hline 53 & Miracema & 26843 & 24741 & 23388 & 92,17 & 1 \\
\hline 54 & Paty do Alferes & 26359 & 18585 & 13062 & 70,51 & 1 \\
\hline 55 & Piraí & 26314 & 20836 & 13797 & 79,18 & 4 \\
\hline 56 & Bom Jardim & 25333 & 15266 & 12202 & 60,26 & 2 \\
\hline 57 & Miguel Pereira & 24642 & 21501 & 13509 & 87,25 & 1 \\
\hline 58 & Itaocara & 22899 & 17326 & 12650 & 75,66 & 1 \\
\hline 59 & Iguaba Grande & 22851 & 22851 & 22851 & 100,00 & 1 \\
\hline 60 & Pinheiral & 22719 & 20411 & 20299 & 89,84 & 1 \\
\hline 61 & Silva Jardim & 21349 & 16121 & 12385 & 75,51 & 1 \\
\hline 62 & Conceição de Macabu & 21211 & 18337 & 18175 & 86,45 & 1 \\
\hline 63 & Cordeiro & 20430 & 19862 & 19862 & 97,22 & 1 \\
\hline 64 & S. J. do Vale do Rio Preto & 20251 & 9007 & 9007 & 44,48 & 6 \\
\hline 65 & Quissamã & 20242 & 12996 & 12996 & 64,20 & 5 \\
\hline 66 & Cantagalo & 19830 & 14022 & 10527 & 70,71 & 2 \\
\hline 67 & Mendes & 17935 & 17701 & 17701 & 98,70 & 1 \\
\hline 68 & Porci·ncula & 17760 & 13890 & 11772 & 78,21 & 1 \\
\hline 69 & Sapucaia & 17525 & 13273 & 5402 & 75,74 & 1 \\
\hline 70 & Carmo & 17434 & 13470 & 12382 & 77,26 & 2 \\
\hline 71 & Rio Claro & 17425 & 13769 & 5904 & 79,02 & 1 \\
\hline 72 & Porto Real & 16592 & 16497 & 15423 & 99,43 & 5 \\
\hline 73 & Natividade & 15082 & 12046 & 10435 & 79,87 & 1 \\
\hline 74 & Sumidouro & 14900 & 5440 & 4172 & 36,51 & 6 \\
\hline 75 & Cambuci & 14827 & 11292 & 5921 & 76,16 & 6 \\
\hline 76 & Italva & 14063 & 10242 & 10242 & 72,83 & 1 \\
\hline 77 & Carapebus & 13359 & 10542 & 10239 & 78,91 & 5 \\
\hline 78 & E. Paulo de Frontin & 13237 & 9523 & 6132 & 71,94 & 2 \\
\hline 79 & Quatis & 12793 & 12029 & 11662 & 94,03 & 2 \\
\hline
\end{tabular}

Geo UERJ - Ano 14, no. 23, v. 1, $1^{\circ}$ semestre de 2012 p. 262-301

ISSN: 1415-7543 E-ISSN: 1981-9021

http://www.e-publicacoes.uerj.br/index.php/geouerj 


\begin{tabular}{|c|c|c|c|c|c|}
\hline Cardoso Moreira & 12600 & 8757 & 7697 & 69,50 & 2 \\
\hline Areal & 11423 & 9923 & 9923 & 86,87 & 2 \\
\hline Duas Barras & 10930 & 7736 & 3949 & 70,78 & 6 \\
\hline Santa Maria Madalena & 10321 & 5932 & 4877 & 57,48 & 1 \\
\hline Trajano de Morais & 10289 & 4780 & 2556 & 46,46 & 1 \\
\hline Aperibé & 10213 & 8878 & 8436 & 86,93 & 1 \\
\hline Varre-Sai & 9475 & 5790 & 5790 & 61,11 & 6 \\
\hline São Sebastião do Alto & 8895 & 4612 & 2077 & 51,85 & 6 \\
\hline Rio das Flores & 8561 & 5959 & 3455 & 69,61 & 1 \\
\hline Com. Levy Gasparian & 8180 & 7862 & 6671 & 96,11 & 5 \\
\hline Laje do Muriaé & 7487 & 5637 & 5637 & 75,29 & 1 \\
\hline São José de Ubá & 7003 & 3098 & 3098 & 44,24 & 6 \\
\hline Macuco & 5269 & 4593 & 4593 & 87,17 & 2 \\
\hline
\end{tabular}

Fonte: IBGE - Censo Demográfico 2010 e Produto Interno Bruto dos Municípios 2008

A dimensão demográfica segundo a população total 2010 (IBGE) é um indicador discriminatório tanto em termos produtivos, como em termos de consumo. O tamanho populacional é utilizado como uma proxy da massa de consumidores. Três tipos são identificados: 1-Municípios de grandes dimensões demográficas - com população total superior a 500 mil habitantes; 2-Municípios de médias dimensões demográficas - com população total entre 250 mil e 500 mil habitantes; 3-Municípios de pequenas dimensões demográficas - com população total inferior a 250 mil habitantes.

A dimensão grau de urbanização, segundo a população urbana total sobre a população total 2010 (IBGE), indica que quanto maior for a proporção de população urbana, maior será a expressão das atividades urbanas: comércio, serviços e indústria. Quatro tipos foram identificados: 1.Muito forte - grau de urbanização acima de 80,0\%; 2.Forte - grau de urbanização entre $80,0 \%$ e 50,0\%; 3.Moderado - grau de urbanização entre 50,0\% e 25,0\%; 4.Fraco - grau de urbanização abaixo de 25,0\%.

A dimensão economica segundo valor adicionado (Produto Interno Bruto) dos municípios 2008 (IBGE) por atividades dos setores economicos, identificou seis tipos: 1.Fortemente de serviços (com mais de 80,0\% do PIB); 2.Serviços forte/médio $(55,0 \%$ a $75,0 \%$ do PIB) + industrial (serviços - 75,0\% e industria - 25,0\% do PIB); 
3.Equilíbrio de PIB maior de serviços sobre PIB industrial; 4.Equilíbrio de PIB maior industrial sobre PIB de serviços; 5. Fortemente industrial e fraco PIB de serviços; 6.Serviços alto/médio/fraco (PIB nos serviços abaixo de 50,0\%) e agrícola médio/baixo (PIB agrícola até 25,0\%).

A tipologia final consistiu no cruzamento matricial da população total do município (Dimensão Demográfica); da relação entre a população urbana e a população total do município (Grau de Urbanização) e do PIB (Dimensão Economica), como pode ser observado no mapa 5, no qual podemos observar a distribuição espacial dos tipos estabelecidos.

Mapa 5: Tipologia dos Municípios Fluminenses 2008/2010

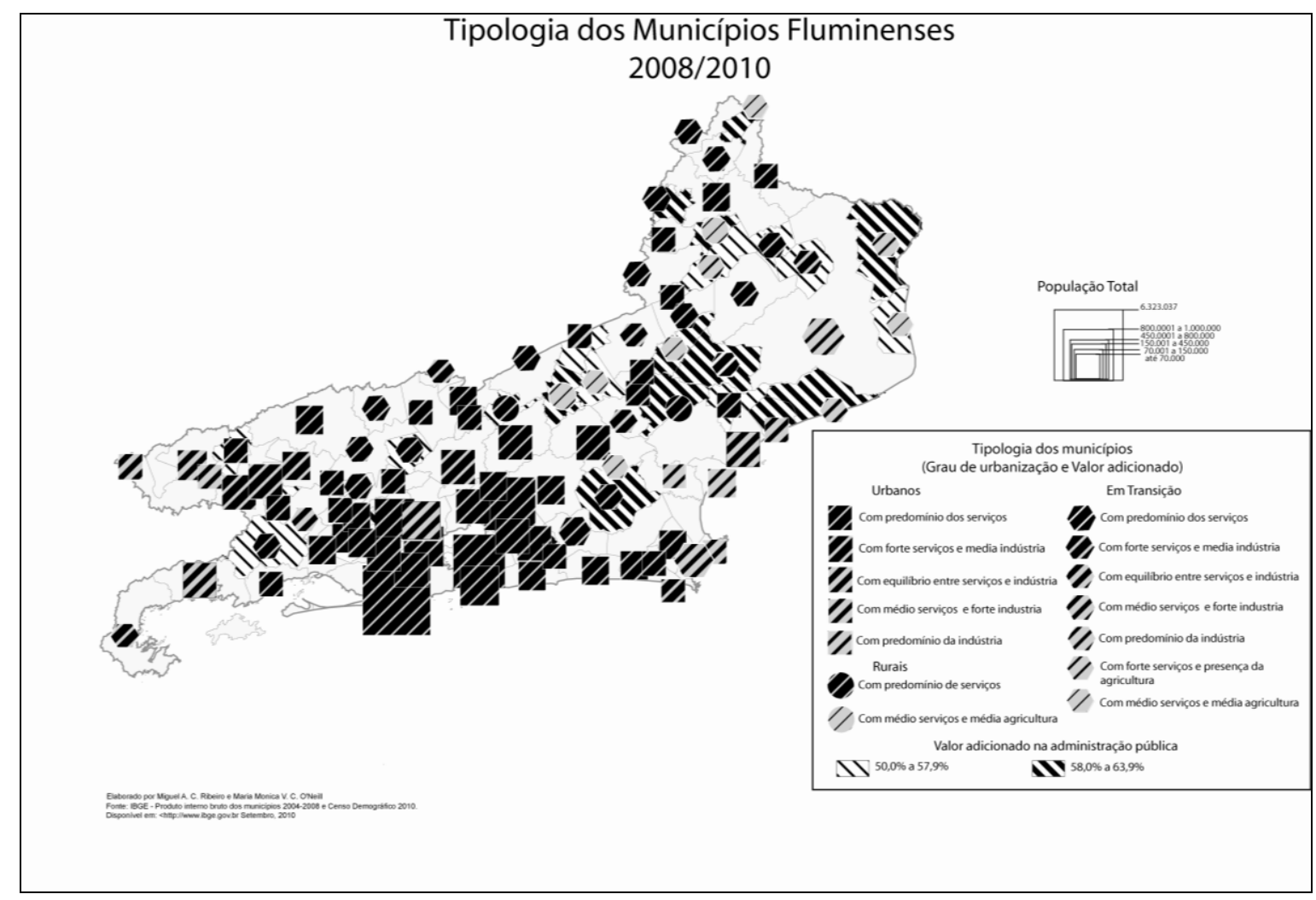

Na tabela 13 estão os respectivos valores dos três indicadores, sendo que dos 92 municípios fluminenses, tomando por base a dimensão economica, segundo o PIB por 
atividades dos setores economicos, 51 municípios estão alocados no tipo 1, no qual há um predomínio do setor de serviços. Neste tipo estão incluídos os municípios nas três classes de dimensão demográfica e com grau de urbanização superior a 45,0\%, predominando 35 com mais de 80,0\% de urbanização. Aqui aparecem os municípios mais importantes economicamente, localizados na Região Metropolitana, tais como Rio de Janeiro, São Gonçalo, Nova Iguaçu, Niterói, São João de Meriti. São municípios que tem sua economia pautada no setor de serviços e no caso da capital fluminense o resultado do PIB registra a segunda maior economia de serviços do país, combinada com uma ampla disponibilidade de serviços de educação, formando como apontou Santos (2003, p.112), “as qualificações para o exercício de controle dos fluxos de capital e de informações, possibilitando a cidade do Rio de Janeiro tornar-se um elo mais importante da rede economica mundial".

Como pode ser comprovado, o tipo 1 corresponde a mais da metade do total dos municípios fluminenses, ratificando o papel eminentemente terciário da economia na atualidade, fato também registrado para o Brasil, acompanhando uma tendência mundial.

Neste conjunto, também aparecem municípios de pequenas dimensões demográficas, que tem sua economia voltada para o comércio, e vinculados a serviços públicos, como saúde, educação e administrativos, exemplificados por Laje do Muriaé, Rio das Flores, Aperibé, Trajano de Morais, Santa Maria Madalena, Italva e Natividade, que registram população inferior a 15 mil residentes.

No tipo 2 estão 18 municípios que conjugam PIB nos serviços e na indústria, distribuídos pelas três classes de tamanho populacional e apresentando grau de urbanização superior a 60,0\%. Neste conjunto podemos destacar Belford Roxo, com a presença da Bayer; Petrópolis, com a indústria de confecções; Volta Redonda, com a CSN (Companhia Siderúrgica Nacional), considerados municípios de grandes dimensões demográficas, e com mais de $95,0 \%$ de sua população urbana. Ainda destacamos neste tipo, Barra Mansa, Queimados, Barra do Piraí, Cachoeiras de Macacu, Parati, entre outros. São municípios que apresentam atividade industrial importante, reforçando o PIB nesta atividade, complementado pelos serviços.

Geo UERJ - Ano 14, n. 23, v. 1, $1^{\circ}$ semestre de 2012 p. 262-301

ISSN: 1415-7543 E-ISSN: 1981-9021

http://www.e-publicacoes.uerj.br/index.php/geouerj 
No tipo 5 somente 8 municípios apresentam forte participação do PIB industrial, destacando-se Campos dos Goytacazes, em função da indústria alimentar, com o beneficiamento do açúcar; Cabo Frio, com presença das salinas e da produção de sal; Rio das Ostras, no qual a indústria da construção civil tem peso importante. Complementam este conjunto, os municípios de São João da Barra, Armação dos Búzios, Quissamã, Porto Real, Carapebus e Comendador Levy Gasparian.

No tipo 6 estão inseridos 9 municípios. Estes seriam, no conjunto dos municípios fluminenses, aqueles que têm suas receitas provenientes do setor primário (valor adicionado da agropecuária), além da presença das atividades de serviços. São municípios considerados de pequenas dimensões demográficas, e em sua maioria acusando grau de urbanização inferior a 50,0\%. Neste tipo estão São Fidélis, São José do Vale do Rio Preto, Sumidouro, Cambuci, Duas Barras, Varre-Sai, São Sebastião do Alto e São José de Ubá. Estes municípios vivem das atividades agrícolas, destacando-se como produtores de café, tomate, além da pecuária, entre outras atividades.

Não poderíamos deixar de fazer menção aos tipos 3 e 4 no qual estão incluídos 6 municípios. São eles: Duque de Caxias, Macaé, Angra dos Reis, Resende, Itatiaia e Piraí, no qual conjugam atividades industriais e de serviços, pesando no PIB municipal, com presença de importantes plantas industriais, tais como a REDUC (Refinaria Duque de Caxias); Petrobras (Base operacional e plataformas); TEBIG (Terminal da Baía da Ilha Grande - Petrobras), o antigo estaleiro Verolme, e as usinas nucleares de Angra 1 e 2 (CORRÊA, 2010; 2012).

Posto isto, podemos concluir esta seção afirmando, a partir de Ribeiro e Cavalcanti (2011), que segundo os critérios de definição de perímetro urbano adotados pelas prefeituras em consonância/dissonância com o IBGE (RUA, 2002), o território fluminense apresenta domínio da população residente urbana sobre a população residente rural, evidenciando a mais elevada taxa de população urbana do país.

Por estes critérios adotados, segundo Rua (2002, p. 50),

a partir da segunda metade dos anos oitenta do século XX, motivado pela descentralização de recursos para a órbita municipal ligada aos novos 
princípios tributários da Constituição de 1988, sempre com a intenção de ampliar a cobrança do IPTU, imposto este de esfera municipal. Consequentemente, os perímetros urbanos são ampliados, e muitas vezes, áreas nitidamente rurais são transformadas em aglomerados urbanos, registrando residentes urbanos e obrigados ao pagamento do referido imposto.

Esta distinção entre a situação urbana e a rural, em grande porção do Brasil, provoca distorções, conduzindo a debates, por parte, de inumeros estudiosos.

Em se tratando do território fluminense, a taxa de urbanização não compromete, de todo essa realidade, como se pode confirmar, a partir da tipologia apresentada, segundo os indicadores considerados: a dimensão demográfica, o grau de urbanização e o PIB. Esta tipologia permite uma aproximação maior dos dados estatísticos com a realidade, não restringindo a taxa de urbanização do país à simples relação entre a população urbana total e a população total de um recorte espacial (país, estado, município).

Neste contexto, os resultados verificados a partir da Tipologia ratificam a situação do estado do Rio de Janeiro apresentar a mais elevada taxa de população urbana nacional, resultado esse explicado pela localização desta unidade federada na região mais concentradora de bens, riquezas e população (SANTOS; SILVEIRA, 2001) - a Sudeste.

Atrelado a esses fatores, é possível reforçar a idéia que a metrópole fluminense amplia o processo de urbanização, anteriomente identificado como uma desconcentração para o interior do Estado, mas obedecendo a um padrão seletivo, pois ocorre apenas ao longo de alguns eixos, como apontado por Rua (2002).

\section{À Guisa de Considerações Finais}

O estado do Rio de Janeiro e sua atual capital históricamente exerceram um papel de liderança nacional, juntamente com São Paulo, em decorrência de fatos políticos e economicos que conduziram o país, de uma sociedade agro-pastoril, para 
uma sociedade urbano-industrial, provocando significativas mudanças nas relações organizacionais e territoriais.

Tais fatores e mudanças podem ser concretamente visualizados no espaço fluminense, uma vez que para a cidade do Rio de Janeiro convergiam os elementos destinados a garantir a realização de suas atividades, tornando seu território um elemento privilegiado na localização de instituições, empresas, infra-estrutura e pessoas, deixando marcas que permanecem ainda hoje (RIBEIRO; O' NEILL, 2001). Consequentemente, o significado e importância nacional da cidade do Rio de Janeiro conduziram ao desenvolvimento de relações assimétricas com o Estado na qual se localiza, gerando um desequilíbrio entre a metrópole carioca e sua hinterlândia, entre o núcleo metropolitano e a periferia, entre o urbano e o rural. Os traços destes desequilíbrios são visíveis ao retratar-se a dinâmica populacional e sua organização espacial em território fluminense.

Posto isto, apesar da concentração populacional ainda se fazer presente na metrópole nesta primeira década do século XXI, o interior fluminense apresenta municípios que vem destacando-se no aumento de sua população, caso verificado com Rio das Ostras e Araruama, que apresentaram no último recenseamento geral valores superiores a 100 mil residentes, juntando-se com aqueles que anteriormente já apresentavam tais cifras, como Angra dos Reis, Teresópolis, Cabo Frio e Macaé, somados aqueles que já apresentavam tais cifras, anteriormente aos anos 1990, como Campos dos Goytacazes, Petrópolis, Volta Redonda, Nova Friburgo e Barra Mansa, cujas economias eram as mais dinâmicas do interior, e consequentemente influenciando na chegada de população para os mesmos, dirigindo-se, principalmente para suas sedes municipais.

Este perfil de concentração populacional na metrópole fluminense ainda vai se manter por muitos anos, pois a discrepância é muito expressiva, mas novos espaços passarão por profundas transformações economicas alicerçadas em investimentos públicos e privados, influenciando no aumento de seus contingentes populacionais, podendo-se mencionar, na parte leste da Região Metropolitana do Rio de Janeiro, a construção do COMPERJ (Petrobras), no município de Itaboraí; o porto do Açu, pelo

Geo UERJ - Ano 14, n. 23, v. 1, $1^{\circ}$ semestre de 2012 p. 262-301 ISSN: 1415-7543 E-ISSN: 1981-9021 http://www.e-publicacoes.uerj.br/index.php/geouerj 
grupo EBX, em São João da Barra e, o porto de Furado, na divisa de Quissamã com Campos dos Goytacazes no Norte Fluminense, entre outros, além da exploração do petróleo no pré-sal, como pode ser registrado na reportagem no Rio Pesquisa (2010) intitulada "Ouro Negro na Mira" e da atividade turística que se faz presente em várias localidades do interior, destacando-se o Vale do Café, mencionado em Caderno Especial do Jornal O Globo (2011) quando da realização do Festival Vale do Café, ocorrido em 14 cidades localizadas nas regiões do Médio Vale do Paraíba e Centro Sul Fluminenses.

Estes empreendimentos, apesar de pontuais, estimularão a interiorização da população, consequentemente mudando a dinâmica populacional vigente, por outro lado, provocarão impactos sócio ambientais irreversíveis, como já vem se manifestando, caso verificado com o Porto do Açu.

\section{Notas}

1. Considera-se como interior, segundo Ribeiro (2002), todos os municípios não incluídos nos limites metropolitanos, não importando sua localização geográfica. Para este autor, o estado do Rio de Janeiro apresenta dois subespaços: a metrópole constituída pelo núcleo e pela periferia e o interior.

2. A taxa média geométrica de crescimento anual da população - incremento médio anual da população, medido pela expressão $i=$ fórmula sendo $\mathrm{P}(\mathrm{t}+\mathrm{n})$ e $\mathrm{P}(\mathrm{t})$ populações correspondentes a duas datas sucessivas, e n o intervalo de tempo entre essas datas, medido em ano e fração de ano. Consulta realizada no site:

http://www.ibge.gov.br/home/estatistica/populacao/condicaodevida/indicadoresminimos /conceitos.shtm

3. No Brasil, desde 1937, considera-se como critério oficial adotado pelo IBGE para caracterizar domicílios urbanos, àqueles localizados nos perímetros distritais (sedes de vilas) e nas sedes municipais (cidades). Os domicílios externos aos limites urbanos são considerados rurais. Portanto, trata-se de um critério político-administrativo, muitas vezes, trazendo distorções e criticas.

Geo UERJ - Ano 14, no. 23, v. 1, $1^{\circ}$ semestre de 2012 p. 262-301

ISSN: 1415-7543 E-ISSN: 1981-9021

http://www.e-publicacoes.uerj.br/index.php/geouerj 
4. Atualmente (fevereiro de 2012) constituem a Região Metropolitana do Rio de Janeiro os municípios: Rio de Janeiro, São Gonçalo, Duque de Caxias, Nova Iguaçu, Niterói, Belford Roxo, São João de Meriti, Magé, Itaboraí, Mesquita, Nilópolis, Queimados, Maricá, Itaguaí, Japeri, Seropédica, Guapimirim, Paracambi, Tanguá, segundo o Censo Demográfico 2010 (IBGE).

5. Segundo a localização do domicílio, a situação pode ser urbana ou rural, definida por lei municipal em vigor em 01/08/2010.

Situação urbana - consideram-se as áreas urbanizadas ou não, correspondentes, às cidades (sedes municipais), às vilas (sedes distritais) ou às Áreas Urbanas Isoladas. A situação rural abrange toda a área situada fora desses limites, inclusive os aglomerados rurais de extensão urbana, os povoados e os núcleos.

Municípios - constitutem unidades autonômas de menor hierarquia na organização político-administrativa do País.

Cidade - localidade de mesmo nome do município a que pertence (sede municipal) e onde esta sediada a respectiva prefeitura.

Vila - localidade de mesmo nome do distrito a que pertence (sede distrital) e onde está sediada a autoridade distrital, excluídos os distritos das sedes municipais (IBGE, Censo Demográfico 2010).

\section{Referências}

BAENINGER, Rosana. Redistribuição Espacial da População e Urbanização: mudanças e tendências recentes. In: Regiões e Cidades, Cidades nas Regiões. s/d, p. 271-88.

CASTRO BARBOSA, Pedro Paulo Biazzo de. A Constituição de uma Periferia em Face da Modernização: a produção de açúcar e álcool no Brasil e as transformações na região norte fluminense. In: Revisitando o Território Fluminense. Rio de Janeiro: NEGEF, 2003, p. 111-48. 
CAVAlCANTI, Vera Maria d'Ávila. Caracterização e Tendências da Rede Urbana do Brasil. Organizado por IPEA / UNICAMP IE. NESUR / IBGE. Campinas, SP: UNICAMP. IE, 1999 (Coleção Pesquisas).

CORRÊA, Renata da Silva. Diferentes Territórios, Territorialidades Divergentes: os territórios do turismo em Angra dos Reis (RJ). In: Revisitando o Território Fluminense III. Rio de Janeiro: Gramma, 2010. p. 113-34.

Transformações socioespaciais em Angra dos Reis e Parati (RJ) de 1960/70 a 2010. 2012. 133f. Dissertação (Mestrado em Geografia) - Instituto de Geografia, Universidade do Estado do Rio de Janeiro, 2012.

DAVIDOVICH, Fany R. Estado do Rio de Janeiro: singularidades de um contexto territorial. In: Território, Rio de Janeiro: LAGET/UFRJ, ano V, 2000, p. 9-24.

IBGE. Censo Demográfico 1991.

IBGE. Censo Demográfico 2000.

IBGE. Censo Demográfico 2010.

IBGE. Produto Interno Bruto dos Municípios 2004-2008, Rio de Janeiro, 2010.

LIMONAD, Ester. Reflexões sobre o espaço, o urbano e a urbanização. In: GEOgraphia, Rio de Janeiro, n. 1, 1999, pp. 71-91.

MARAFON, Glaucio José; RIBEIRO, Miguel Angelo. Agricultura Familiar, Pluriatividade e Turismo Rural: reflexões a partir do território fluminense. In: Revista Rio de Janeiro. Rio de Janeiro: UERJ/Fórum-Rio, v. 1, n. 1, set/dez, 1985, p. 111-30.

MARAFON, Glaucio José; RIBEIRO, Miguel Angelo. Revisitando o Território Fluminense III. Rio de Janeiro: Gramma, 2010. 332p.

MARTINE, George. Migração e Metropolização. In: Revista São Paulo em Perspectiva. São Paulo, Fundação Seade, v. 1, n. 2, 1987, p. 7. 
MORAIS, Alex Pereira de. Considerações sobre o Papel dos Royalties e Participações Especiais de Petróleo e Gás sobre a Economia dos Municípios Confrontantes com a Bacia de Campos. In: Revisitando o Território Fluminense III. Rio de Janeiro: Gramma, 2010, pp.243-73.

NATAL, Jorge (org.). Conjuntura Fluminense Recente 2: memórias selecionadas 20042008. Rio de Janeiro: Armazém das Letras, 2009, 250p.

O GLOBO. Vale do Café. 14 de julho de 2011.

O GLOBO. Cidades. In: Razão Social nº 136, 2012, p.14.

O’ NEILL, Maria Monica Vieira Caetano. Relação Rural-Urbano, 2011 (mimeo).

OLIVEIRA, Antonio Tadeu Ribeiro de; ERVATTI, Leila Regina; O’ NEILL, Maria Mônica Vieira Caetano. O panorama dos deslocamentos populacionais no Brasil: PNADs e Censos Demográficos. In: Reflexões sobre os deslocamentos populacionais no Brasil. IBGE. Organização: Luiz Antonio Pinto de Oliveira e Antonio Tadeu Ribeiro de Oliveira. Col. Estudos \& Análises, n. 1, 2011, pp. 29-49.

PESQUISA RIO. Ouro Negro na Mira. FAPERJ, ano 3, n. 10, março de 2010, p. 29-33. PIQUET, Rosélia; GIVISIEZ, Gustavo Henrique Naves; OLIVEIRA, Elzira Lúcia de. A Nova Centralidade de Campos dos Goytacazes: o velho e o novo no contexto regional. In: Revista Rio de Janeiro, v. 1, n. 1, set/dez 1985, p. 39-57.

PORTELLA, Eduardo de Sá. A Centralidade de Campos dos Goytacazes: uma análise a partir do ensino superior. In: Revisitando o Território Fluminense III. Rio de Janeiro: Gramma, 2010, p. 275-93.

RAMIRES, Júlio Cesar de Lima. As Grandes Corporações e Dinâmica Socio-espacial: a ação da Petrobras em Macaé. In: Revista Brasileira de Geografia, 53(4), 1991, p. 11551.

RIBEIRO, Miguel Angelo. Considerações sobre a Dinâmica Populacional no Estado do Rio de Janeiro. 2001. 20p. (mimeo). 
RIBEIRO, Miguel Angelo. Considerações sobre o Espaço Fluminense: estrutura e transformações. In: Estudos de Geografia Fluminense. Rio de Janeiro: Infobook/UERJ, 2002, p. 13-26.

RIBEIRO, Miguel Angelo; CAVALCANTI, Vera Maria d' Ávila. Tipologia Urbana no Estado do Rio de Janeiro ao Final do Milênio. In: As Cidades e a Urbanização no Brasil: passado, presente, futuro. Florianópolis: Insular, 2011, p. 147-58.

RIBEIRO, Miguel Angelo; COELHO, Maria do Socorro Alves. A Importância do Fenômeno da Segunda Habitação e suas Implicações com a atividade de lazer-veraneio: o exemplo do estado do Rio de Janeiro. In: Agricultura, desenvolvimento e transformações socioespaciais: reflexões interinstitucionais e constituição de grupos de pesquisa no rural e no urbano. Uberlândia: Assis Editora, 2008, pp. 30318.

RIBEIRO, Miguel Angelo; O’ NEILL, Maria Mônica Vieira Caetano. Atlas do Estado do Rio de Janeiro. Instituto de Geografia/UERJ, 2001, cd-room.

RUA, João. Urbanização em áreas rurais no estado do Rio de Janeiro. In: Estudos de Geografia Fluminense. Rio de Janeiro: Livraria e Editora Infobook Ltda., 2002, pp. 43-69.

SANTOS, Angela Moulin S. Penalva. Economia, Espaço e Sociedade no Rio de Janeiro. Rio de Janeiro: Editora FGV, 2003. 228p.

SANTOS, Milton. A urbanização brasileira. São Paulo: HUCITEC, 1993, 157p.

SANTOS, Milton; SILVEIRA, Maria Laura. O Brasil: território e sociedade no início do século XXI. Rio de Janeiro: Record, 2001, 471 p.

VEIGA, José Eli. A face rural do desenvolvimento: natureza, território e agricultura. Porto Alegre: UFRGS, 2000, 197 p.

WANDERLEY, M. de N. B. A Emergência de uma Nova Ruralidade nas Sociedades Modernas Avançadas: o "rural” como espaço singular e ator coletivo. In: Estudos Sociedade Agricultura. Seropédica: Universidade Federal do Rio de 
Janeiro, Programa de Pós-Graduação em Desenvolvimento Agricultua e Sociedade, n. 15, p. 87-147, outubro. 2000.

Artigo encaminhado para publicação em março de 2012.

Artigo aceito para publicação em maio de 2012.

Geo UERJ - Ano 14, nº. 23, v. 1, $1^{\circ}$ semestre de 2012 p. 262-301

ISSN: 1415-7543 E-ISSN: 1981-9021

http://www.e-publicacoes.uerj.br/index.php/geouerj 